\begin{tabular}{|l|l|}
\hline Las razones del neodesarrollismo (respuesta a F. H. Cardoso y J. Serra) (1978) & Titulo \\
\hline Marini, Ruy Mauro - Autor/a & Autor(es) \\
\hline América Latina, dependencia y globalización & En: \\
\hline Buenos Aires y Bogotá & Lugar \\
\hline $\begin{array}{l}\text { CLACSO, Consejo latinoamericano de Ciencias Sociales } \\
\text { Siglo del Hombre Editores }\end{array}$ & Editorial/Editor \\
\hline 2008 & Fecha \\
\hline & Colección \\
\hline $\begin{array}{l}\text { Industrializacion; Revolucion; Imperialismo; Marxismo; Lucha de clases; Capitalismo; } \\
\text { Dependencia Económica; Centro- Periferia; Socialismo; América Latina; Brasil; }\end{array}$ & Temas \\
\hline Capítulo de Libro & Tipo de documento \\
\hline http://bibliotecavirtual.clacso.org.ar/clacso/se/20100830092707/06razones.pdf & URL \\
\hline $\begin{array}{l}\text { Reconocimiento-No comercial-Sin obras derivadas 2.0 Genérica } \\
\text { http://creativecommons.org/licenses/by-nc-nd/2.0/deed.es }\end{array}$ & Licencia \\
\hline
\end{tabular}

Segui buscando en la Red de Bibliotecas Virtuales de CLACSO

http://biblioteca.clacso.edu.ar

Consejo Latinoamericano de Ciencias Sociales (CLACSO)

Conselho Latino-americano de Ciências Sociais (CLACSO)

Latin American Council of Social Sciences (CLACSO)

www.clacso.edu.ar

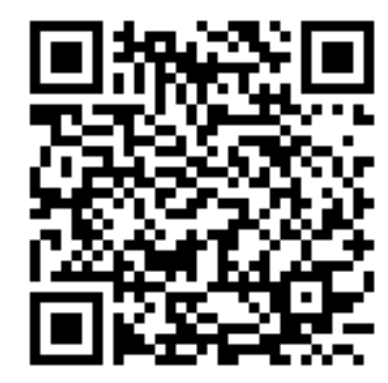


Marini, Ruy Mauro. Las razones del neodesarrollismo (respuesta a F. H. Cardoso y J. Serra) (1978). En publicación: América Latina, dependencia y globalización. Fundamentos conceptuales Ruy Mauro Marini. Antología y presentación Carlos Eduardo Martins. Bogotá: Siglo del Hombre - CLACSO, 2008. ISBN 978-958-665-109-7

Disponible en: http://bibliotecavirtual.clacso.org.ar/ar/libros/secret/critico/marini/06razones.pdf 


\section{LAS RAZONES DEL NEODESARROLLISMO (RESPUESTA A F. H. CARDOSO Y J. SERRA $)^{1}$}

"Las desventuras de la dialéctica de la dependencia" es un trabajo escrito por José Serra y Fernando Henrique Cardoso con el objetivo de criticar mis planteamientos sobre el capitalismo dependiente, en particular el brasileño. El título del trabajo, como lo señalan sus autores, se inspira en el de un libro de Maurice Merleau-Ponty, publicado a principios de la década pasada, que ponía "la corona de espinas" en "la cabeza de quienes, bien o mal, buscaban adaptar la herencia clásica a las experiencias de la construcción del socialismo y, en el afán de justificar lo injustificable, distorsionaban sus ideas". En realidad, se trataba de un ataque a Jean-Paul Sartre, a raíz de su acercamiento al Partido Comunista. Aunque Sartre no se molestó en darle una respuesta a Merleau-Ponty — quien ganara notoriedad al pretender conferir rango filosófico al anticomunismo de Arthur Koestler-, éste recibió la que merecía por la mano de Simone de Beauvoir.

Tras señalar que el trabajo se escribió en enero de 1978, cuando prestaban servicios en una institución norteamericana, y agradecer los comentarios de otros intelectuales brasileños - en especial del Centro Brasileño de Análisis y Planeamiento (CEBRAP),

1 Extraído de Revista Mexicana de Sociología, número especial, México, Facultad de Ciencias Políticas y Sociales, UNAM, 1978, pp. 57-106. 
creado por Cardoso-, los autores explican la finalidad del mismo. Éste pretende "poner trancas que cierren las falsas salidas" en el análisis de la realidad, para lo que se abocará a la crítica de mi "ambiciosa teoría" sobre el capitalismo dependiente, con la intención de lograr "la destrucción eventual de algunos o aun de todos los principales supuestos" de la misma. Para ello, se divide en cuatro capítulos: "Desarrollo nacional y estancamiento económico", "El intercambio que no es bien igual", "El subimperialismo y las tinieblas" y "la 'teoría' de la superexplotación del trabajo (o la plusvalía que nunca es relativa)", que se acompañan de un "cuasi epílogo". Los dos primeros tratan de algunas cuestiones generales, los dos últimos versan sobre el desarrollo capitalista reciente en Brasil.

En su conjunto, constituye un texto desaliñado y truculento, que deforma casi siempre mis planteamientos para poder criticarlos, manipula los datos que utiliza (o no utiliza) y que brilla por la falta de rigor, la torpeza e incluso el descuido en el manejo de hechos y conceptos. El lector lo entenderá mejor si toma en cuenta que va dirigido fundamentalmente a la joven generación brasileña, que conoce poco o casi nada de lo que he escrito. Esto es lo que lleva a los autores no sólo a "exponer" mi pensamiento, sino también a permitirse adaptarlo libremente a los fines que se han propuesto. Seguramente habrían procedido de otra manera si se dirigieran a un público más familiarizado con las tesis en cuestión.

En las consideraciones que sobre dicho texto presentaremos a continuación, utilizaremos el original en portugués. Nos esforzaremos, siempre que ello no violente demasiado la lógica de la exposición, en seguir el orden temático allí adoptado, manteniéndonos dentro de su enfoque, es decir, predominantemente económico. Advertimos al lector que, por tratarse de la respuesta a una crítica específica, limitaremos a lo esencial nuestra argumentación, sin pretender retomar planteamientos que en otras oportunidades hemos hecho sobre el capitalismo dependiente latinoamericano y brasileño; en este sentido no se contempla aquí la totalidad, y ni siquiera los elementos principales, de lo que hemos expuesto en otros textos. 
"Las desventuras..." empieza con un paso desafortunado. Constatando que mis planteamientos tienen como eje la cuestión del socialismo en América Latina, busca enmarcarlos en la tesis sustentada por sectores intelectuales de la década pasada, respecto a la inevitabilidad del estancamiento económico en la región. Incurre, con ello, en un doble equívoco: no es cierto que yo suscribiera entonces esa tesis - como tampoco la suscribo hoy - ni la misma se relacionaba directamente con el tema del socialismo. De pasada, confunde estancamiento y crisis ("La aurora revolucionaria tendría como incubadora el acicate del estancamiento y la crisis" $)^{2}$ sin comprender que las crisis, para un marxista, corresponden a saltos del capitalismo hacia su destrucción, pero no se confunden con el estancamiento, sino todo lo contrario: resultan de la acumulación capitalista misma, es decir, del desarrollo capitalista.

La "prueba" de mi adhesión a la tesis del estancamiento latinoamericano se presenta ${ }^{3}$ - tras lo que parece ser una autocrítica implícita de Cardoso por haberla compartido-en los tiempos en que preocupaban los problemas del "subcapitalismo", y se cifra en esta cita de un texto mío:

Todo está en lograr una organización de la producción que permita el pleno aprovechamiento del excedente creado, vale decir que aumente la capacidad de empleo y producción dentro del sistema, elevando los niveles de salario y de consumo. Como esto no es posible en el marco del sistema capitalista, no queda al pueblo brasileño sino un camino: el ejercicio de una política obrera, de lucha por el socialismo. ${ }^{4}$

2 José Serra y Fernando Henrique Cardoso, "Las desventuras de la dialéctica de la dependencia", en Revista Mexicana de Sociología, número extraordinario, México, 1978, p. 3.

3 José Serra y Fernando Henrique Cardoso, "Las desventuras de la dialéctica de la dependencia”, op. cit., p.1.

4 Ruy Mauro Marini, Subdesarrollo y revolución, México, Siglo XXI, 1974. $5^{\text {a }}$ edi- 
A primera vista, el texto citado parece dar razón a "Las desventuras..." pero ¿qué es lo que está en...? ¿En qué contexto se hizo la afirmación? Veamos:

[el] desarrollo económico [...] no puede ser logrado, como pretende la "burguesía nacional", obstaculizando la incorporación del progreso tecnológico extranjero y estructurando la economía con base en unidades de baja capacidad productiva. Para las grandes masas del pueblo, el problema está, inversamente, en una organización económica que no sólo admita la incorporación del progreso técnico y la concentración de las unidades productivas, sino que las acelere, sin que ello implique agravar la explotación del trabajo en el marco nacional y subordinar definitivamente la economía brasileña al imperialismo. ${ }^{5}$

Este párrafo citado antecede al recorte que se hizo en "Las desventuras...". Como se dará cuenta el lector, allí no se trataba para nada de estancamiento: se polemizaba con una posición política que - ante el carácter monopólico y la decidida integración al imperialismo que caracterizaban a la economía brasileña-levantaba un proyecto pequeñoburgués, estrechamente nacionalista y antimonopólico, y se sostenía que la lucha (no la agitación de un modelo abstracto) contra el gran capital nacional y extranjero sólo podría ser una lucha dirigida por la clase obrera y que tendiera al socialismo. Para mayor abundamiento, señalemos que dicho pasaje pertenece a la sección del libro intitulada "La dialéctica del desarrollo capitalista en Brasil", en la cual se analizan las luchas de clases que desembocaron en el golpe militar de 1964 y la forma subimperialista que asume entonces dicho desarrollo. "El capitalismo brasileño — - se decía, un poco más atrás— se ha orientado así hacia un desarrollo monstruoso, etcétera". ${ }^{6}$

ción aumentada, p. 104. El capítulo correspondiente se publicó, originalmente, como artículo: "La dialéctica del desarrollo capitalista en Brasil", en Cuadernos Americanos, CXLVI-3, México, mayo-junio de 1916, pp. 133-155.

5 Ibid., pp. 103-104.

6 Ibid., pp. $101 \mathrm{y}$ ss. Esa falta de honestidad en el uso del material criticado, que 
La segunda clase de equívocos a que da lugar "Las desventuras..." está en suponer que se puede establecer, en general, una ligazón entre la tesis del "estancamiento" y la ideología socialista de la década pasada, en Latinoamérica. Es cierto que los autores se corrigen más adelante, ejemplificando con algunas citas de Helio Jaguaribe. Pero a) no sólo queda la impresión general de que las luchas por el socialismo que se libraron entonces estuvieron guiadas por la idea de la imposibilidad del desarrollo capitalista, sino que b) se oscurece el carácter real de la crisis que sacudió el pensamiento latinoamericano a mediados de la década. El primer error hace caso omiso de las luchas de clases desatadas en el continente, desde los años cincuenta, que, alcanzando su primer punto culminante con la Revolución Cubana de 1959, continúa hasta hoy. El segundo no da cuenta del verdadero carácter de la crisis experimentada por las ciencias sociales latinoamericanas en los sesenta, ni de las corrientes entonces surgidas (que se tiende a englobar, incorrectamente, bajo la designación genérica de estudios sobre la dependencia).

El golpe militar brasileño de 1964 tuvo, para la década pasada, una importancia similar al golpe chileno de 1973 para la actual. Representó, como señalé entonces, el fracaso de una política: el reformismo, bajo su forma populista y nacionalista; y de

caracteriza a "Las desventuras...", es aún más flagrante en la consecuencia que los autores sacan de esa cita, en el sentido de que "ese tipo de análisis ayudó a racionalizar los argumentos por parte de la izquierda latinoamericana a lo largo de los años sesenta y comienzos de los setenta” (José Serra y Fernando Henrique Cardoso, "Las desventuras de la dialéctica de la dependencia", op. cit., p. 7), añadiendo en una nota que dicha racionalización puede ser encontrada en Ruy Mauro Marini, Subdesarrollo y revolución, op. cit., en el pasaje correspondiente a "Los supuestos de la lucha armada" (pp. 133-141). "Las desventuras..." no dice que dicho pasaje es... juna crítica a los supuestos de la práctica armada de la izquierda brasileña de la época! Hay muchas razones por las cuales denunciarme como partidario de la lucha armada, pero afirmar que mi toma de posición al respecto se deriva de la tesis del "estancamiento" constituye como mínimo una aserción desventurada. 
una clase: la burguesía nacional. ${ }^{7}$ Los partidos comunistas, que habían apostado en esta carta, atribuyeron los sucesos contrarrevolucionarios de Brasilia a una trama diabólica del imperialismo norteamericano. Los intelectuales que, ligados al establishment (sea directamente en el gobierno de João Goulart, sea en instituciones internacionales como la CEPAL), habían pregonado la ideología del desarrollo capitalista autónomo (generando así, desde el lado patronal, una táctica que coincidía con la del PC) manifestaron perplejidad e impotencia. Un buen ejemplo de ello es el caso de Celso Furtado, ex funcionario de la CEPAL del gobierno de Goulart, quien, en su calidad de principal teórico del estancamiento, proclamó el cierre definitivo de la industrialización y el regreso de Brasil a la condición de exportador de bienes primarios. ${ }^{8}$ En un texto más agudo, pero igualmente desesperado, el cepalino Anibal Pinto, sin adherir a la tesis del estancamiento, constató que el pretendido desarrollo autónomo no había conducido sino a la monopolización de la economía por el gran capital nacional y extranjero y propuso una política dirigida por el Estado, de apoyo a la media y pequeña burguesía, aun a costa de que esto implicara frenar el desarrollo del sector moderno (monopólico), es decir, obstaculizar objetivamente las tendencias del desarrollo capitalista. ${ }^{9}$

7 Ruy Mauro Marini, Subdesarrollo y revolución, op. cit., p. 57. El capítulo correspondiente apareció, como artículo, en un número de 1965 de la revista Foro Internacional, México.

8 Anibal Pinto, "Brasil: de la república oligárquica al Estado militar", en Brasil boy, México, Siglo XXI, 1966.

9 "Concentración del progreso técnico y de sus frutos en el desarrollo latinoamericano”, en El Trimestre Económico, México, No. 125, enero-marzo de 1965, pp. 3-69. Pinto expresa su concepción (en el fondo, correcta) de una manera todavía confusa y en lenguaje cepalino, al distinguir un polo "dinámico" y otro "tradicional", que no se caracterizaban ya por el corte entre la agricultura y la industria, sino que dividían horizontalmente toda la estructura económica. Ese nuevo dualismo está presente en el trabajo de Cardoso y Faletto, Dependencia y desarrollo en América Latina, México, Siglo XXI, 1969, y dio lugar a posteriores elaboraciones sobre temas específicos, como el de la llamada "marginalidad social”. 
Ahora bien, esa crisis del pensamiento desarrollista no tenía por qué afectar a la joven intelectualidad brasileña, que militaba en las filas de la izquierda revolucionaria, surgida al margen del PC, a principios de la década. El eje de los planteamientos de esa izquierda era la crítica a la estrategia de ese partido, que postulaba la colaboración de clases entre la burguesía nacional y el proletariado en pro de una revolución democrático-burguesa, antiimperialista y antifeudal. En el curso de su desarrollo, la izquierda revolucionaria había roto con el nacional-desarrollismo burgués, ruptura que dio lugar a una nueva elaboración teórica, que se vierte en una literatura estrictamente partidaria. Esto sólo comienza a modificarse, dando lugar a trabajos de carácter más personal, cuando la violenta depuración de las universidades, medios de comunicación y del propio aparato del Estado, por las fuerzas golpistas, empieza a expulsar del país a muchos de los intelectuales de esa izquierda.

Coincidiendo con ello, la crítica del desarrollismo ganó un carácter más amplio. Intelectuales no militantes, como André Gunder Frank y el mismo Cardoso, basándose en los planteamientos teóricos de la izquierda revolucionaria, se lanzaron también a la discusión sobre las tesis cepalinas y funcionalistas. Aportaron así elementos a la construcción de una nueva teoría explicativa de la realidad latinoamericana, aunque algunos de ellos contribuyeron a conferir un carácter académico a un debate que, en sus orígenes, era primariamente político, limitando con ello la radicalidad de la crítica. Es en particular el caso de Cardoso, en su trabajo en colaboración con Faletto, no sólo por los compromisos conceptuales y de lenguaje que mantiene con el desarrollismo, como han señalado otros, sino sobre todo por la absoluta ausencia de una teoría del imperialismo que se observa en dicho texto. ${ }^{10}$ Convie-

10 Cardoso y Faletto manejan la relación de la economía dependiente con la economía mundial siempre en función del concepto cepalino de "sector externo", lo que no les permite relacionar cómo las tendencias y leyes del capitalismo operan en una y otra ni cómo se articulan entre sí. Posteriormente Cardoso trató de integrar en sus trabajos ese nivel de análisis, que ya estaba presente en las elaboraciones de la izquierda revolucionaria brasileña; vienen de allí sus conceptos 
ne señalar que nada, en esa clase de textos, lleva a identificar el "cambio social" con la revolución socialista.

Es a ese distinto origen de las nuevas corrientes intelectuales que se gestaron en la década de 1960, así como al tipo de compromiso que ellos asumieron, que se debe la profunda división que se registra hoy entre los que trabajaron, bien o mal, de la misma manera la elaboración de un nuevo marco de conocimiento de nuestras sociedades.

INTERCAMBIO DESIGUAL Y SUPEREXPLOTACIÓN:

ALGUNAS PRECISIONES

El aparato siguiente de "Las desventuras..." se refiere indiscriminadamente a cuestiones que tienen que ver con el intercambio desigual y con la superexplotación del trabajo. El propósito de mis "críticos" es demostrar que el intercambio desigual, tal como yo lo analizo, no es tal ni conduce a que los países dependientes reaccionen contra él recurriendo a la superexplotación del trabajo (aunque la causa primaria de ésta no resida allí, como lo he indicado). ${ }^{11}$ Veremos, más adelante, cómo se las arreglan para hacer esa demostración, procediendo primero a algunas rectificaciones.

Se trata de probar que es absurdo mi razonamiento en el sentido de que las exportaciones latinoamericanas de alimentos, al reducir el valor del capital variable y aumentar por consiguiente la composición de valor del capital, agravan la tendencia a la baja de la cuota de ganancia en los países capitalistas avanzados. Para este fin, y valiéndose incluso de las matemáticas, "Las desventuras..." demuestra que, al bajar el capital variable, crecen la masa y la cuo-

de "desarrollo autónomo" y "desarrollo asociado", tomados prestados a los de "desarrollo autónomo" y "desarrollo integrado" que yo utilizara en el artículo de 1965 citado, así como apoyados en el que se publicó originalmente con el título de "Brazilian Interdependence and Imperialist Integration", en Montbly Review, Nueva York, diciembre de 1965.

11 Ruy Mauro Marini, Dialéctica de la dependencia, México, Ediciones Era, 1973, pp. 24-49. 
ta de plusvalía, así como, por consiguiente, de ganancia. Lo que es obvio. Agregan nuestros "críticos": "No sería lógico suponer, por otro lado, que porque disminuye $\mathrm{V}$, gracias a las exportaciones latinoamericanas de alimentos, $C$ tendría que subir" ${ }^{12}$

No, no sería en absoluto lógico suponer que, porque baja el capital variable, por la causa señalada, el capital constante debe aumentar. Sin embargo, mis desventurados "críticos", el punto del que parto es rigurosamente el opuesto: el de que la exportación latinoamericana de alimentos se realiza en función de la revolución industrial europea y coadywva (no determina de manera exclusiva) la baja del capital variable, necesaria para que la elevación de la productividad, sobre la base del aumento del capital constante, no presione hacia abajo la cuota de ganancia. ${ }^{13}$ Como indiqué en el texto, esto corresponde a la inserción dinámica de América Latina en la división mundial del trabajo impuesta por la gran industria, que permitió a los países avanzados concentrarse en la producción de materias primas industriales. El Quijote combatía contra molinos de viento, que creía ser gigantes; mis "críticos" tienen más el espíritu de Sancho: edifican sus propios molinos para enfrentarlos sin tener que apelar a la valentía.

En la distorsión de mis planteamientos, "Las desventuras..." no utiliza sólo el método de la inversión, sino también el de la adición. Así, considera que yo supongo que la producción latinoamericana para la exportación aumentó "en condiciones necesarias de productividad decreciente (o estancada)", suposición que no se encuentra en ninguno de mis textos. Lo único que sostengo es que, en condiciones de intercambio marcadas por una neta superioridad tecnológica de los países avanzados, las economías dependientes debieron echar mano de un mecanismo de compensación que, permitiendo el aumento de la masa de valor y plusvalía realizada, así como de su cuota, contrarrestara al menos parcialmente las pérdidas de plusvalía a que tenían que sujetarse;

\footnotetext{
12 José Serra y Fernando Henrique Cardoso, "Las desventuras de la dialéctica de la dependencia", op. cit., p. 16 (cursivas de los autores).

13 Ruy Mauro Marini, Dialéctica de la dependencia, op. cit., p. 26.
} 
ese mecanismo fue la superexplotación del trabajo. ${ }^{14}$ Ésta explica el fuerte desarrollo de la economía exportadora latinoamericana, pese al intercambio desigual. Es de suponerse que mis "críticos" no pretendan que, ante la transferencia de valor que éste implicaba, las economías latinoamericanas pudieran reaccionar mediante la elevación de su nivel tecnológico a un ritmo igual al que lo hacían los países avanzados. Ello no implica ni mucho menos que su productividad se haya estancado o decrecido, sino que fue siempre a la zaga. Tampoco hay que derivar de lo dicho lo que no se ha dicho: la superexplotación del trabajo es acicateada por el intercambio desigual, pero no se deriva de él, sino de la fiebre de ganancia que crea el mercado mundial, y se basa fundamentalmente en la formación de una sobrepoblación relativa. Pero, una vez en marcha un proceso económico sobre la base de la superexplotación, se echa a andar un mecanismo monstruoso, cuya perversidad, lejos de mitigarse, es acentuada al recurrir la economía dependiente al aumento de la productividad mediante el desarrollo tecnológico. ${ }^{15}$

14 Cfr. Ibid., pp. 40-41. Señalemos que el aumento del número de trabajadores a que se refieren mis "críticos" en "Las desventuras de la dialéctica de la dependencia”, op. cit., p. 20, pese a que fue abundantemente utilizado en América Latina, no tiene que ver con el tema de la superexplotación: a circunstancias iguales, deja invariable la cuota de plusvalía, pudiendo afectar tan sólo la cuota de ganancia.

15 Analizando el efecto de la prolongación de la jornada de trabajo y su relación con el descenso del precio del trabajo, dice Marx: "Este poder de disposición sobre una cantidad anormal de trabajo no retribuido - anormal porque rebasa el nivel social medio- pronto se convierte en motivo de competencia entre los propios capitalistas. Una parte del precio de la mercancía está tomada por el precio del trabajo. La parte no retribuida del precio del trabajo no necesita figurar como primer paso que impulsa a dar la concurrencia. El segundo paso impuesto por ésta consiste en desglosar también del precio de venta de la mercancía una parte por lo menos de la plusvalía anormal, conseguida mediante la prolongación de la jornada de trabajo. De este modo se va formando, primero esporádicamente y luego de un modo cada vez más estable, un precio anormalmente bajo de venta de la mercancía que, si en un principio era el fruto de los salarios raquíticos y de las jornadas excesivas, acaba por convertirse en base constante de estos fenómenos”. Karl Marx, El capital, México, Fondo de Cultura Económica, 1946-1947 t. I, p. 460, cursivas mías. Esto vale para cualquier procedimiento que implique 
De todos modos, mis "críticos" se preocupan aquí menos de la cuestión de la superexplotación que de mis planteamientos respecto al intercambio desigual. Desde este punto de vista, lo primero que llama la atención es que, aunque vayan a "criticar" lo que he dicho sobre el tema, hacen la curiosa advertencia de que no contemplarán el problema de la transferencia de valor a través del comercio exterior. ${ }^{16}$ La razón básica que dan para ello es que "no habiendo movilidad de la fuerza de trabajo, es difícil establecerse, en escala internacional, el concepto de tiempo de trabajo socialmente necesario, el cual, a su vez, es crucial como requisito para la operación de la ley del valor". ${ }^{17}$

Detengámonos un poco en este párrafo. La movilidad de la fuerza de trabajo no influye para nada en el concepto de tiempo de trabajo socialmente necesario, a escala nacional o internacional. Seguramente mis "críticos" quieren decir que afecta su determinación, su medición. Pero tampoco es así: a nivel nacional o internacional, el tiempo de trabajo socialmente necesario no se determina por la circulación de la fuerza de trabajo, sino que es exclusivamente función del desarrollo de las fuerzas productivas, del grado de destreza, productividad e intensidad media de la fuerza de trabajo en la producción. Lo único que cabe a la circulación es comparar los tiempos de trabajo socialmente necesarios para la producción de las mercancías, es decir, comparar los valores de éstas; sobre esta base se determina el precio comercial de cada una, es decir, se establece entre ellas una relación de precios que, por mucho que varíe por acción de la oferta y/o la demanda, gira en torno a la comparación de los valores.

La circulación o no circulación de la fuerza de trabajo nada tiene que ver, pues, con la vigencia de la ley del valor. El único efecto que puede derivarse de la movilidad internacional de ma-

aumentar la masa de trabajo impago y explica las diferentes estructuras de precios que rigen entre países con distinto grado de desarrollo capitalista.

16 José Serra y Fernando Henrique Cardoso, "Las desventuras de la dialéctica de la dependencia”, op. cit., p. 16.

17 Ibid. 
no de obra se refiere a los precios de producción, al favorecer en ese plano la formación de la ganancia media.

¿Podría la circulación internacional de la fuerza de trabajo afectar el tiempo de trabajo socialmente necesario y, en consecuencia, la determinación del valor? Desde luego que sí, cuando permita el flujo de fuerza de trabajo con calificación; de nada le serviría a un país importar un operador de tractores si lo condena a trabajar con una hoz. Pero, aunque la fuerza de trabajo calificada se inserte positivamente en un proceso de producción, ello no modifica el papel de la circulación de mercancías, que seguirá imperturbablemente comparando valores que han variado por cambios en el plano de la producción, tal como lo haría si estos valores no bubieran variado. En cualquier hipótesis, la comparación de valores se expresa en una relación de precios, que, más o menos influidos por la circulación, siguen referidos al valor. Si mis desventurados "críticos" contaran con conocimientos elementales sobre la relación valor-precio no necesitarían descubrir triunfalmente que "los dos intercambios no son bien iguales", o sea, lo obvio: que el valor no es lo mismo que el precio. Pero tampoco se escandalizarían de que los índices de precios puedan ser tomados como indicadores de valores, sobre todo para períodos largos (en que las variaciones de la circulación tienden a neutralizarse), y de que, por ende, al analizar el intercambio desigual es lícito y necesario recurrir al examen de la evolución de los precios relativos $o$, lo que es lo mismo, a los términos de intercambio.

El hecho de no contar con esos conocimientos elementales lleva a los autores de "Las desventuras..." a afirmaciones sorprendentes. Es así como, al discutir el efecto de las variaciones de precios en la cuota de ganancia de países con distinto grado de desarrollo, sostienen que, al aumentar los precios de los productos de los países de mayor desarrollo, dicha cuota no tendría por qué reducirse en el país de desarrollo inferior, pues

[...] la importación de productos manufaturados continuaría realizándose por el mismo precio por unidad de producto industrializado. Lo que ocurre de hecho no es el encarecimiento absoluto de 
los productos industriales, sino el mantenimiento de su precio de venta, pese a la reducción de su valor unitario. ${ }^{18}$

Como vemos, mis "críticos" suponen que los movimientos de precios no implican movimientos de valor; de tal manera que, al mantenerse el precio de mercado por encima del valor, esto no implicaría una transferencia de valor por parte de aquel que lo adquiriera, dando en cambio una mercancía cuyo precio se mantuviera a la par con su valor. Llegamos, pues, a un punto en que no sólo los intercambios no son "bien iguales", sino que son ¡absolutamente diferentes!

El párrafo que sigue ${ }^{19}$ no merece mayor atención: si se está diciendo que, el aumento de la productividad y de la reducción del valor unitario de la mercancía no afectan la cuota de ganancia, si la reducción del valor unitario se compensa con el aumento de la masa de valor producida, acorde con la inversión adicional que propició la elevación de la productividad, se está descubriendo el huevo de Colón y no habrá quien quiera decir lo contrario. Pero esto nada tiene que ver con la superexplotación del trabajo. Ésta implica que, sin variación del valor unitario, aumente la masa de valor producido y/o apropiado por el capitalista, y ambos casos comportan aumento de la cuota de plusvalía. El aumento del valor apropiado, sin aumento de la masa de valor producido, corresponde a la reducción del salario sin una reducción equivalente del tiempo de trabajo necesario para que el obrero reponga el valor del mismo; el aumento de la masa de valor producido y apropiado resulta del aumento de la masa de trabajo rendido por el obrero, vía prolongación de la jornada de trabajo o intensificación del trabajo. En su concepto, la superexplotación se expresa pues en el incremento de la cuota de plusvalía sobre la base de una masa mayor de plusvalía y un valor unitario constante; la única excepción, que la acerca al aumento de la explotación sobre la base de una mayor productividad del trabajo, deriva del aumento de in-

\footnotetext{
18 Ibid., p. 17 (cursivas de los autores).

19 Ibid.
} 
tensidad, el cual, si se generaliza a toda la rama de producción y se estabiliza en un nivel superior, conduce a la reducción del tiempo de trabajo socialmente necesario para producir la mercancía y, en consecuencia, a la reducción de su valor unitario.

Hasta ahora nos hemos limitado a examinar los intentos de "Las desventuras..." por criticar, en el plano teórico, mis planteamientos respecto al intercambio desigual y la superexplotación del trabajo, intentos que se frustran por el hecho de que éstas son incapaces de plantear correctamente la relación entre valor y precio, además de confundir sistemáticamente cuota de ganancia con cuota de plusvalía. Pero, en un momento, "Las desventuras..." cambia el enfoque para preocuparse de las implicaciones de la superexplotación en el desarrollo histórico del capitalismo mundial. En este sentido, además de arrumbar en pie de página algunos datos sobre el comercio exterior inglés, levanta una serie de cuestiones: la determinación del valor de la fuerza de trabajo en Inglaterra (¿por qué se supone que los obreros ingleses no comían carne?); la composición y el destino de las exportaciones latinoamericanas (¿por qué se supone que Inglaterra no importaba trigo de América Latina?); las formas de explotación en países como Argentina y Uruguay (¿por qué el hecho de no tener los "peores niveles de vida" implica que no haya superexplotación del trabajo?). Como se ve, demasiados problemas para que los tratemos ligeramente. Nos limitaremos, pues, a señalar la metodología que debe seguir una investigación rigurosa sobre el problema planteado por "Las desventuras...", la cual comprende los siguientes pasos:

a) definir si, como plantea Marx, el comercio exterior, al abaratar el capital constante y/o el capital variable, incide en la composición del valor del capital y, por ende, en la cuota de ganancia;

b) explicar por qué los países avanzados han recurrido, para este fin, a las importaciones desde países atrasados (donde es menor la productividad del trabajo y, en consecuencia, es mayor la masa de trabajo incorporada a las mercancías, vale decir, su va- 
lor), así como los mecanismos que permitieron que estos pudieran vender barato lo que en principio producían caro;

c) analizar la composición y el destino de las exportaciones de América Latina, así como la evolución de los precios relativos de su intercambio con los países avanzados;

d) tener en cuenta que, pese a la importancia de Inglaterra, América Latina no se integra propiamente a este país, sino al mercado mundial, y que otros mercados diferentes del inglés tuvieron importancia decisiva en la integración de países latinoamericanos, como el norteamericano para Chile —en cierto período- o Brasil, el alemán para Colombia, etc., y

e) ponderar adecuadamente la contribución de las exportaciones latinoamericanas al mercado mundial, considerando las transferencias de valor circulares, o indirectas, que implican que un valor cedido por Brasil y Estados Unidos, por ejemplo, pueda ser apropiado finalmente por Inglaterra, gracias a sus transacciones con este país. ${ }^{20}$

\section{MARXISMO Y SOCIOLOGISMO}

Consideremos, finalmente, la cuestión de fondo que plantea "Las desventuras...", en este apartado. En efecto, pese a sus lucubraciones económicas, éstas no niegan "la diferencial de salarios en perjuicio de los trabajadores de la periferia", ${ }^{21}$ aunque el enredo que hace con la cuota de ganancia y de plusvalía le impida plantearse seriamente la cuestión de si ello representa o no una superexplotación de esos trabajadores; tampoco niega la existencia del intercambio desigual, ${ }^{22}$ aunque tampoco pueda llegar a una

20 La necesidad de considerar globalmente los movimientos del comercio internacional, puesta en evidencia por algunos autores, es enfatizada por André Gunder Frank en su ensayo "Desequilíbrios do comércio multilateral de mercadorias e desenvolvimento econômico regular"; véase su libro Acumulação, dependência e subdesenvolvimento, Lisboa, Iniciativas Editoriais, 1977.

21 José Serra y Fernando Henrique Cardoso, "Las desventuras de la dialéctica de la dependencia”, op. cit., p. 15.

22 Ibid., p. 20. 
conclusión definitiva sobre el mismo, debido a su confusión entre valor y precio, así como entre producción y circulación. Pero sus infortunadas incursiones en materia económica son, en cierto sentido, marginales respecto a la tesis que sustenta, como la de que el "fundamento dinámico" de esos fenómenos es la lucha de clases ${ }^{23}$ o lo "básico" es "la dinámica que se deriva de la lucha entre las clases". ${ }^{24}$ Nos encontramos, pues, de nuevo, con el enfoque sociologista del ya mencionado trabajo de Cardoso y Faletto, que ha ganado nuevos bríos en América Latina con la difusión de las tesis de la escuela althusseriana y los coletazos del maoísmo.

Ahora bien: cualquier marxista sabe, con Marx y Engels, que la historia de la humanidad es la historia de la lucha de clases y, con Lenin, que la lucha de clases es el único terreno en que un marxista se mueve con firmeza. Sin embargo, esto no quiere decir que la lucha de clases se explique por sí misma o, si se quiere, que sea el Deux ex machina que permite explicarlo todo. Más bien, para un marxista la tarea reside siempre en el plano del análisis abstracto como en el del concreto, en conocer qué es lo que explica la lucha de clases, y esto remite, necesariamente, al examen de las condiciones materiales en que ella se da. Esas condiciones - que se captan mediante conceptos y se rigen por leyes y tendencias objetivas- generan contradicciones, que no son, ni mucho menos, "parámetros económicos" que "el juego político hace moverse en una o otra dirección”. ${ }^{25}$ La lucha de clases es la sintesis de las condiciones en que los hombres hacen su existencia, y se encuentra, por esto mismo, regida por leyes que determinan su desarrollo. Es por lo que la relación entre teoría y práctica constituye el eje de la dialéctica marxista.

$\mathrm{Al}$ sostener que la historia es la historia de la lucha de clases, Marx no se limitó a describir la lucha de clases: se esforzó por distinguir los modos de producción que constituyen su fundamento y dedicó toda su vida al estudio de las leyes del modo de produc-

\footnotetext{
23 Ibid., p. 15.

24 Ibid., p. 20.

25 Ibid.
} 
ción capitalista, para armar al proletariado —-teórica, ideológica e políticamente- en su lucha de clase contra la burguesía. Construyó un aparato conceptual para explicar la lucha de clases que se ejerce en ese modo de producción; así, por ejemplo, el concepto de valor de la fuerza de trabajo es la clave para el análisis de la lucha de clases entre obreros y capitalistas, en el plano económico, en la cual los primeros pelean por un salario que respete ese valor, y los segundos entienden que "la gratitud del obrero es un limite en sentido matemático, que nunca puede alcanzarse, aunque sí pueda rondarse"; $; 6$ pero ese concepto no sirve para explicar la lucha de clases en una sociedad esclavista ni tampoco en una sociedad feudal, a las que sólo se puede aplicar por extensión, ya que es una categoría típica de un modo de producción basado en el trabajador asalariado libre. Al esclavo no se le ocurrirá reclamar al esclavista el pago del valor de su fuerza de trabajo, por el simple hecho de que ésta no se paga y, en cierto sentido, no reviste para él un valor, así como su trabajo le parece una actividad que realiza parcialmente para sí; ${ }^{27}$ reclama simplemente el derecho a disponer de su persona, lucha por su libertad.

Prosigamos: es precisamente porque, en cada época de la humanidad, la lucha de clases se rige por leyes específicas que se hace necesario construir el instrumental teórico que nos permita explicar su desarrollo. Según el nivel de análisis, más abstracto o más concreto, el énfasis se desplaza hacia la manera como las leyes generales se realizan a través de la lucha de clases o hacia el modo como la lucha de clases actúa sobre la realización de esas leyes. Un marxista sabe que una y otra manera de enfocar el problema no es más que eso: enfoques impuestos por el nivel del análisis, y es porque la lucha de clases es la expresión de contradicciones que se rigen por leyes específicas que es tan necesario no contentarse

\footnotetext{
26 Karl Marx, El capital, t. I, p. 506.

27 "En el trabajo de los esclavos, hasta la parte de la jornada en que el esclavo no hacía más que reponer el valor de lo que consumía para vivir y en que por tanto trabajaba para sí, se presentaba exteriormente como trabajo realizado para su dueño. Todo el trabajo del esclavo parecía trabajo no retribuido”. Karl Marx, El capital, t. I, p. 452.
} 
jamás con la descripción de la forma aparencial de la lucha de clases, sino más bien armarse de conceptos rigurosos que permitan iluminar sus determinaciones profundas.

Sin embargo, por elevado que sea el nivel de abstracción, el análisis marxista está siempre informado por la lucha de clases y remite necesariamente a ella. En ningún momento el análisis marxista se detendrá en la descripción neutral de un hecho, por más ajeno que parezca ser a la acción de los hombres, ni perderá de vista sus implicaciones por las relaciones que sobre la base de ese hecho estos establecen entre sí, relaciones que en una sociedad de clases se expresan siempre en la lucha de clases. Y es esto lo que lo distingue de los análisis no marxistas, por más que estos, ante la incapacidad de explicar una realidad social dada, recurran al "ábrete sésamo" de la lucha de clases, que en este caso no abre, sino que cierra la puerta al tesoro del conocimiento. Así, un marxista no se contenta con decir que

[...] los aumentos de productividad en la producción de M (máquinas textiles, por ejemplo) son rápidos — dado que el progreso técnico tiende a penetrar y difundirse con mayor vigor y amplitud en las actividades industriales - y no se traducen en reducción proporcional significativa del precio unitario de $\mathrm{M}$, [mientras que] los aumentos de productividad en la producción de $\mathrm{P}$ (café, por ejemplo) son más lentos — dada la naturaleza de las actividades primarias $-\mathrm{y}$ tienden a reflejarse en reducciones proporcionales de los precios. ${ }^{28}$

Los aumentos de productividad en la industria son rápidos porque el progreso técnico se difunde con mayor vigor en las actividades industriales, son lentos en la producción primaria dada la naturaleza de las actividades primarias: se trata de descripciones ya ni siquiera neutrales, sino tautológicas. Nada de eso nos explica la dinámica del progreso técnico en las diferentes esfe-

28 José Serra y Fernando Henrique Cardoso, "Las desventuras de la dialéctica de la dependencia”, op. cit., p. 9 (exponiendo tesis de la CEPAL). 
ras de la producción. Para hacerlo, un marxista toma la relación entre trabajo vivo y trabajo muerto y la aplica a la producción de materias primas y alimentos, así como a la producción manufacturera, y constata que en la primera prima el trabajo vivo, la acción directa del hombre sobre la naturaleza, mientras que en la segunda se amplía la parte que cabe al trabajo muerto (materias primas e instrumentos de trabajo). ${ }^{29}$ Esto le permite entender la tendencia de la economía dependiente, productora de materias primas y alimentos, a reposar más en la explotación del trabajo como tal y, en la medida en que tiene en ésta "su fuente inmediata de nueva acumulación", ${ }^{30}$ hacer que la acumulación dependa en mayor grado de la explotación de la fuerza física del trabajador mediante la incorporación de más fuerza de trabajo a la producción (lo cual puede implicar el aumento del número de trabajadores, lo que, en circunstancias iguales, aumenta la masa de valor sin alterar la cuota de plusvalía, o la prolongación de la jornada de trabajo y/o la intensificación del trabajo, lo que hace variar positivamente una y otra).

Pero sigamos examinando las tesis que reivindican "Las desventuras...": decir que los aumentos de productividad en la industria "no se traducen en reducciones de precios", mientras que eso sí pasa en la agricultura, no sólo no explica nada, sino que es falso. Si queremos saber cómo el aumento de la productividad actúa sobre los precios internacionales, es necesario tener presente que

[...] en el mercado mundial, el trabajo nacional más productivo se considera al mismo tiempo como más intensivo, siempre y cuando que la nación más productiva no se vea obligada, por la concurrencia, a rebajar el precio de venta de sus mercancías hasta el límite de su valor. ${ }^{31}$

\footnotetext{
29 Karl Marx, El capital, t. I, cap. XXII.

30 Ibid., p. 509.

31 Ibid., pp. 469-470.
} 
En otras palabras: aunque la productividad reduzca el valor unitario de la mercancía, ésta puede venderse en el mercado mundial por encima de su valor, si la concurrencia no actúa en sentido contrario. "La jornada más intensiva de trabajo de una nación se traduce en una expresión monetaria más alta que la jornada menos intensiva de otro país" ${ }^{32}$ Es ésta la razón fundamental por la cual las relaciones entre las economías capitalistas avanzadas y dependientes, al expresar relaciones de intercambio entre sistemas productivos con distintos niveles tecnológicos y, por ende, con distintas intensidades medias de trabajo, normalmente hacen que se operen transferencias de valor vía precios, es decir, que se realice un intercambio desigual que corresponde, a la vez, al deterioro de los términos de intercambio en perjuicio de las últimas. Y es por esto, también, que éstas tienen que recurrir, como medida de compensación, a aumentar la magnitud extensiva e intensiva del trabajo que explotan, o sea, a los métodos de superexplotación del trabajo referidos a la producción.

Los autores de "Las desventuras..." se darán cuenta, ahora, que hacer reverencias a la lucha de clases no es la panacea para los problemas del conocimiento (menos aún cuando ésta es olvidada en la primera ocasión que se presenta, en favor de proposiciones tautológicas que la excluyen) y que las cuestiones que los preocupan en este apartado se rigen por leyes económicas objetivas, que la CEPAL nunca fue capaz de formular. El enfoque sociologista, por atractivo que parezca, no nos permitirá jamás saber por qué la clase obrera de los países capitalistas avanzados ha podido librar su lucha de clase con mejores resultados que la de las economías capitalistas dependientes. Para entenderlo hay que tomar en cuenta "la presión sorda de las condiciones económicas”, como diría Marx.

\section{II}

Los apartados III y IV de "Las desventuras..." se refieren a lo que constituye el objeto central del trabajo: refutar algunos de mis

32 Ibid., p. 439. 
planteamientos sobre el carácter y las tendencias del desarrollo capitalista reciente en Brasil. Aquí se abandona el ya reducido decoro que la "crítica" había conservado en las partes precedentes: la truculencia se acentúa y los falseamientos no se limitan ya a la interpretación distorsionada de mis textos, sino que sencillamente los mutilan o alteran. Unos cuantos ejemplos serán suficientes.

En "Las desventuras..." citan: "se asiste en toda América Latina a la resurrección de la vieja economía primario-exportadora", 33 remitiendo a la Dialéctica de la dependencia, donde se lee: "se asiste en toda América Latina a la resurrección de la vieja economía exportadora". ${ }^{34}$ Mas adelante citan: "se cierra cualquier posibilidad de estímulo a la inversión" ${ }^{35}$ en el sector de bienessalarios; la frase dice: "se cierra cualquier posibilidad de estímulo a la inversión tecnológica" en dicho sector. ${ }^{36}$ Tras remitirse a un pasaje referente a la relación entre la realización de la producción industrial y las remuneraciones de los trabajadores ${ }^{37}$ señalan que, para "rectificar o al menos precisar mejor", el análisis, yo añadí un párrafo; ${ }^{38}$ en realidad, la primera cita se refiere a un determinado período (la industrialización hasta la década de 1940) y la segunda a otro (la que, con nuevo carácter, se desarrolla en los cincuenta y sesenta), estando dicho corte histórico claramente especificado en el texto. ${ }^{39}$ También citan: "el aumento de la productividad

33 José Serra y Fernando Henrique Cardoso, "Las desventuras de la dialéctica de la dependencia", op. cit., p. 28 (cursivas de los autores).

34 Véase Ruy Mauro Marini, Dialéctica de la dependencia, op. cit., p. 75.

35 José Serra y Fernando Henrique Cardoso, "Las desventuras de la dialéctica de la dependencia”, op. cit., p. 41, lo que se repite en p. 44.

36 Véase Ruy Mauro Marini, Dialéctica de la dependencia, op. cit., p. 43; mis "críticos" subrayan cualquier, pero la palabra clave en la frase es estímulo.

37 José Serra y Fernando Henrique Cardoso, "Las desventuras de la dialéctica de la dependencia”, op. cit., p. 27. Véase Ruy Mauro Marini, Dialéctica de la dependencia, op. cit., p. 64.

38 Véase Ruy Mauro Marini, Dialéctica de la dependencia, op. cit., p. 72.

39 Véase "El nuevo anillo de la espiral", en Dialéctica de la dependencia, op. cit., p. 66. 
conducida por la técnica no puede traducirse en ganancias" 40 (en el sector de producción suntuaria); el párrafo dice:

[...] toda vez que no representan bienes que intervengan en el consumo de los trabajadores, el aumento de productividad inducido por la técnica en esas ramas de producción no ha podido traducirse en mayores ganancias a través de la elevación de la cuota de plusvalia, sino tan sólo mediante el aumento de la masa de valor realizado. ${ }^{41}$

En "Las desventuras..." se refieren a un pasaje en que explico que el aumento de la productividad, al reducir el valor individual de las mercancías, afecta negativamente la plusvalía, calificándolo de absurdo. ${ }^{42}$ Veamos el contexto de la afirmación. El extracto de "Las desventuras..." es tomado de un extenso razonamiento sobre el efecto de la productividad del trabajo como tal y su empleo como método de producción de plusvalía por el capital, donde señalo que, dada esa característica de la productividad (la reducción del valor individual de la mercancía), la cuota de plusvalía no se afecta negativamente si el capital logra extraer más trabajo (es decir, una mayor cantidad de mercancías y, en consecuencia, una masa acrecentada de valor). Esto implica necesariamente mantener la jornada de trabajo (pese a que la productividad reduce el tiempo de producción de la mercancía) y/o aumentar la

40 José Serra y Fernando Henrique Cardoso, "Las desventuras de la dialéctica de la dependencia", op. cit., p. 40.

41 Ruy Mauro Marini, Dialéctica de la dependencia, op. cit., p. 72. Sobre esta base, mis "críticos" se permiten debitar al lector una engolada digresión sobre el papel del capital constante en la elevación de la cuota de ganancia, de que trata el libro II de El capital en su primera sección, y concluir enfáticamente: "Así, Marini reveló desconocer el papel que puede presentar el progreso técnico en la producción de mercancías que integran el capital constante y de allí en la elevación de la productividad y la cuota de ganancia" (José Serra y Fernando Henrique Cardoso, "Las desventuras de la dialéctica de la dependencia", op. cit., p. 39, cursivas mías). Cualquier lector que conozca mi texto sabe que de lo que trato allí es del capital variable, de métodos de producción de plusvalía que no tienen que ver con el aumento de la productividad y de la cuota de plusvalía.

42 José Serra y Fernando Henrique Cardoso, "Las desventuras de la dialéctica de la dependencia”, op. cit., p. 38, nota 40. 
intensificación del trabajo (pese a que la productividad reduce el esfuerzo físico necesario para la producción de la mercancía); en consecuencia, "lo que aparece, en el plano de la producción, como una disminución del tiempo de producción, se convierte, desde el punto de vista del capital, en aumento de la producción exigida al trabajador". 43

Observemos que ese razonamiento se hizo precisamente en el contexto de una crítica a Cardoso, quien, en polémica conmigo, opuso tajantemente el aumento de la plusvalía relativa (Cardoso quería referirse a la productividad del trabajo) al incremento de la explotación de la fuerza física del trabajador, admitiendo implícitamente que "el capitalismo, a medida que se aproxima a su modelo puro, se convierte en un sistema cada vez menos explotador y logra reunir las condiciones para solucionar indefinidamente sus contradicciones internas". 44 "Las desventuras..." no hace más que confirmar que yo tenía razón al atribuir a Cardoso esa visión idílica y apologética del capitalismo.

Este penoso recuento podría prolongarse, pero la muestra basta para que se juzgue el grado de honestidad y de seriedad de mis "críticos". Vayamos, pues, a lo que "Las desventuras..." pretende demostrar en esos dos apartados: que el esquema de realización de la economía subimperialista brasileña, tal como lo

43 Ruy Mauro Marini, Dialéctica de la dependencia, op. cit., pp. 95-96, cursivas en el original. Sobre el asunto, Marx hace una observación que debiera hacer reflexionar a los autores de "Las desventuras..." “YY ésta es la gracia de la economía apologética! Los antagonismos y las contradicciones inseparables del empleo de la maquinaria no brotan de la maquinaria misma, sino de su empleo capitalista. Y puesto que la maquinaria, de por sí, acorta el tiempo de trabajo, mientras que, empleada por el capitalista, lo alarga; puesto que de suyo facilita el trabajo, mientras, aplicada al servicio del capitalismo, refuerza más todavía su intensidad... etc., el economista burgués declara lisa y llanamente que el examen de la maquinaria como tal demuestra de un modo preciso que todas aquellas contradicciones palpables son una simple apariencia de la realidad vulgar, porque no existen de por sí ni por tanto tampoco en la teoría. En vista de esto, no se molesta en quebrarse la cabeza y, encima, achaca al adversario la necesidad de no combatir el empleo capitalista de la maquinaria, sino la maquinaria misma. Karl Marx, El capital, t. I, pp. 366-367.

44 Ruy Mauro Marini, Dialéctica de la dependencia, op. cit., p. 98. 
he planteado, es falso y que ésta no supone la superexplotación de los trabajadores. Recordemos brevemente que, de acuerdo con mi planteamiento, dicho esquema de realización reposa en el mercado externo, el consumo interno suntuario y la demanda estatal. ${ }^{45}$ La tesis de mis "críticos" es que tanto el mercado externo como el Estado han actuado en el sentido de absorber demanda y que, aunque no nieguen el desarrollo del consumo suntuario, se debe hablar, más bien, de expansión del mercado interno en general, que del grado de explotación de los trabajadores, no siendo el mismo, a su modo de ver, un obstáculo para que estos hayan contribuido a dicha expansión.

Señalamos, inicialmente, la manera equivocada como "Las desventuras..." plantea la discusión: su preocupación es la demanda interna, la mía es la demanda global que exige la producción capitalista brasileña. Adicionalmente, la suposición de que yo afirmo que los trabajadores no participan del mercado interno es una caricatura, establecida con base en los procedimientos que reseñé anteriormente. Lo que sostengo es, simplemente, que la superexplotación, al restringir el consumo popular, no lo convierte en factor dinámico de realización y lleva a que las ramas orientadas al consumo popular "tiendan al estancamiento e incluso a la regresión" 46 o se expandan con base en el mercado mundial: "La exportación de manufacturas, tanto de bienes esenciales como de productos suntuarios, se convierte, entonces, en la tabla de salvación de una economía incapaz de superar los factores disruptivos que la afligen". ${ }^{47}$

Observemos que, al hablar de estancamiento y regresión, no tengo en mente el monto absoluto de la producción, sino tasas de crecimiento ${ }^{48}$ no descarto, pues —-lo que sería ridículo—, que las

45 Cfr. Ruy Mauro Marini, Subdesarrollo y revolución, op. cit., parte IV, en particular pp. 198-200. "Las desventuras..." cita ese texto en su versión en inglés: "Brazilian Subimperialism”, en Monthly Review, Nueva York, febrero de 1972.

46 Ruy Mauro Marini, Dialéctica de la dependencia, op. cit., p. 73.

47 Ibid., p. 75.

48 Cfr. Ibid., pp. 73-74. 
ramas que producen para el consumo popular sigan creciendo, y mucho menos supongo — como "Las desventuras..." dice que "insinúo" (sic)_ que el capitalismo dependiente se encuentre "al borde del colapso debido a la progresiva elevación de los precios de bienes-salarios". ${ }^{49} \mathrm{Mi}$ tesis central, sobre la que insisto en todos mis textos, es otra: el capitalismo dependiente, basado en la superexplotación del trabajo, divorcia el aparato productivo de las necesidades de consumo de las masas, agravando así una tendencia general del modo de producción capitalista; ello se expresa, en el plano de la diversificación del aparato productivo, en el crecimiento monstruoso de la producción suntuaria respecto al sector de producción de bienes necesarios, y por ende, en la distorsión equivalente que registra el sector de producción de bienes de capital.

\section{EL ESTADO COMO FACTOR DE REALIZACIÓN DE MERCANCÍAS}

Aclarado lo anterior, vayamos a la argumentación de "Las desventuras..." respecto a su propia tesis sobre la realización de mercancías en el capitalismo brasileño. Aunque no sea lo mejor, sigamos el orden de esa argumentación, empezando con el Estado y preocupándonos inicialmente de su papel como promotor de demanda en general; luego trataremos la pretendida identidad que, según mis "críticos", yo establecería entre gasto público y gastos militares.

Lo primero que llama la atención en el razonamiento de "Las desventuras..." no es ya tanto su falta de rigor, como su torpeza o mala fe. Así, analizando los gastos generales del Gobierno como porcentaje del PIB, por principales rubros (cuadro 1$),{ }^{50}$ sostienen que el incremento de 1,4\% del total observado entre 1959 y 1973 podría "probablemente haberse dado antes de 1964", para en

\footnotetext{
49 José Serra y Fernando Henrique Cardoso, "Las desventuras de la dialéctica de la dependencia”, op. cit., pp. 41-42.

50 El autor hace mención de un cuadro del texto de José Serra y Fernando Henrique Cardoso, que no se incluye en esta antología ( N. del E.).
} 
seguida decir que ese incremento "se explicó primordialmente por la elevación de los gastos de transferencias [...] cuyo destino principal fue el financiamiento de la construcción de viviendas (vía FGTS —Fondo de Garantía de Tiempo de Servicio—)"; de este modo, un incremento que "puede" haberse dado antes de 1964 es achacado a un instrumento creado en 1967... Más abajo afirman que los subsidios se redujeron (lo que, pese a ser sólo una media verdad, como veremos, no puede ser verificado por el lector, ya que el cuadro los presenta agregados a transferencias, en un ítem que se eleva de 5,1\% a 8,9\% en el período), y proponen como una de las causas de esa reducción el "cambio en la política de precios de las empresas públicas", cuidándose de no explicitar a qué empresas se refieren; la misma preocupación les hace pasar por alto el hecho aparentemente sorprendente de que se reduce también la parte del Estado en la formación de capital fijo.

Lo primero que debe señalarse es que el análisis correcto del gasto público stricto sensu, es decir, presupuestario, no puede hacerse mediante fechas tomadas aparentemente al azar. Un estudio más cuidadoso muestra otra cosa: la elevación de la curva del gasto público a partir de 1943, que hizo que en la década 1939-1949 éste subiera de 17,8\% a 19,4\% respecto al PIB. En 1959 correspondía ya a un $22,8 \%$ y seguiría subiendo en la década de 1960 , para alcanzar un $23,4 \%$ en 1964 y, luego, un 24,8\% en 1968, pese a la severa restricción a que fue sometido en el marco de la política antiinflacionaria del gobierno de Castelo Branco.$^{51} \mathrm{El}$ mismo estudio presenta la cifra de 32,2\% para el año 1969, la cual, tras ser aceptada por Werner Baer (uno de los autores que "Las desventuras..." utilizan para construir su cuadro 1), es corregida por éste a $34 \% .^{52}$ En todos los casos se manejan datos oficiales.

51 Fernando Antonio Rezende da Silva, "A evolução das funções do Governo e a expansão do setor público brasileiro”, en Pesquisa e Planejamento, No. 2, Río de Janeiro, diciembre de 1971, pp. 244-247.

52 Werner Baer, Isaac Kerstenetzky y Aníbal V. Villela, "As modificações no papel do Estado na economia brasileira”, en Pesquisa e Planejamento, No. 4, Rio de Janeiro, diciembre de 1973, pp. 898 y 905. 
Como se ve, el problema es un poco más complejo. Sin embargo, es efectivo que el gasto público presupuestario no presenta actualmente, en Brasil, tendencia ascendente, e incluso ha sufrido una reducción después de la década de 1960. La razón de su crecimiento entre los años 1940-1964 se explica por el carácter del Estado, que expresaba el compromiso de la burguesía agraria y mercantil con la burguesía industrial en su conjunto, siendo, para usar una expresión de sabor jruschoviano, un Estado de toda la burguesía. Esto lo llevaba a abusar del gasto e incurrir frecuentemente en el déficit, subsidiando de manera no discriminatoria a la burguesía y beneficiando también a la pequeña burguesía, clase de apoyo del sistema de dominación, así como de manera mucho más limitada, a la misma clase obrera. Estos beneficios empezaron a cortarse desde que con el golpe militar se alteró la alianza de clases que sostiene al sistema de dominación, mientras, a nivel del Estado, se imponía la hegemonía del gran capital nacional y extranjero; a partir de entonces, la misma burguesía se ha visto sometida a mecanismos de subvención selectivos y discriminatorios, que juegan en favor de la fracción monopólica hegemónica. ${ }^{53}$

Ahora bien, en las condiciones de crisis económica, que venía desde 1962 pero que se agudizó a mediados de la década, y de hegemonía aún no consolidada del gran capital, el Estado se ha visto seguramente forzado a usar con prudencia esos mecanismos selectivos y a mantener incluso gastos superfluos - en las nuevas condiciones de alianza de clases- para no agravar hasta el límite la política recesiva puesta en práctica por el entonces ministro de Planeaminento, Roberto Campos. El alza que se observa en el presupuesto, en 1969, aunque parezca desmesurada y deba ser sometida a verificación, es congruente con el filopopulismo del gobierno de Costa e Silva y con las modificaciones de la política económica, que desde 1967 se hiciera más flexible para alentar la expansión. La intensa lucha de clases de ese período y el cuestio-

53 Como, por ejemplo, los llamados incentivos fiscales y crediticios a las exportaciones, principalmente de manufacturados, así como a las inversiones y ampliaciones destinadas a este fin. 
namiento a la fracción hegemónica, dentro del bloque dominante, constituyen sin duda factores que pueden haber provocado el aumento del gasto público. Esta situación se modificó en el curso de 1969 con el ascenso del tercer gobierno militar, el de Garrastazu Médici, el cual consagra, ya en un marco de expansión económica, la hegemonía del gran capital y consolida las tendencias que, en el ámbito de la acumulación como de su realización, se habían gestado en los seis años anteriores; en esas condiciones es comprensible la contención del gasto público en favor de las medidas discriminatorias de subvención al gran capital. ${ }^{54}$

Queda en evidencia que el simple manejo de datos empíricos, desprovistos de la significación que les da la lucha de clases, como se hace en "Las desventuras...", más que facilitar, dificulta la comprensión de las cosas - y esto sería cierto aun si esos datos se manejaran de manera estadísticamente correcta—. Más grave, sin embargo, es el hecho de que, al proceder así, "Las desventuras..." se está esforzando por escamotear aspectos fundamentales para el análisis del problema. En efecto, al analizar el papel del Estado como promotor de demanda, deja en la sombra una cuestión de extrema importancia: las empresas estatales (paraestatales o mixtas); señalemos de paso que, dadas las cifras que manejan nuestros "críticos", no incluyen en el gasto público el de los gobiernos municipales y sus empresas, lo que deja también fuera sumas cuantiosas, como las que moviliza, por ejemplo, el municipio de São Paulo.

Veamos lo relativo a las empresas estatales. En 1971, entre las 25 mayores firmas de Brasil, en términos de activos, 17 pertenecían al gobierno y acaparaban el 82\% de los activos del grupo, así como el $31 \%$ de las ventas. ${ }^{55}$ El Estado tenía en sus manos, respecto al valor de los activos de la rama, el $72 \%$ en la industria

54 Un análisis de la coyuntura 1964-1970 puede encontrarse en Ruy Mauro Marini, Subdesarrollo y revolución, op. cit., partes III y IV.

55 Salvo indicación contraria, estos datos y los que siguen sobre el papel del Estado en la economía brasileña están tomados de Werner Baer, Isaac Kerstenetzky y Aníbal V. Villela, "As modificações no papel do Estado na economia brasileira”, op. cit. 
siderúrgica, el $60 \%$ en la minería de hierro, el $81 \%$ en la explotación, refino y distribución de petróleo; tenía, además, el cuasi monopolio del transporte ferroviario y de las comunicaciones, y controlaba cerca del $70 \%$ del transporte marítimo. Reemplazaría los subsidios presupuestarios por subsidios que no constituyen directamente desembolsos, como los incentivos fiscales (que equivalían a cerca de la mitad de la recaudación por concepto de impuestos directos) y crediticios. Disponía del control del crédito y contaba con el mayor banco comercial del país: el Banco do Brasil (el cual, según la publicación francesa Le Nouvel Économiste de junio de 1977, pasó a ocupar el año pasado el décimo lugar en el ranking mundial de organismos de crédito, con depósitos por 22.000 millones de dólares, un balance total de 39.000 millones y un monto de créditos concedidos del orden de 32.000 millones de dólares), cuatro instituciones federales de crédito y 32 bancos comerciales y de fomento.

Ignorar este conjunto de elementos, cuando se trata de evaluar el impacto del Estado en el proceso de realización de mercancías, parece realmente inconcebible. Aún más porque, en el plano del simple dato empírico, el gasto total del sector público -incluyendo las empresas estatales y excluyendo los gobiernos municipales y sus empresas- representó en 1969 el $50 \%$ del PIB. Aun considerando que posteriormente la parte relativa al gasto presupuestario bajó, ocurrió lo opuesto con el de las empresas públicas, lo que incluso sirvió de pretexto para que, después de 1974, la burguesía de São Paulo levantara una campaña contra la "estatización de la economía". Más importante todavía que el gasto total es la participación del Estado en la inversión fija, que expresa el monto de demanda que el Estado y sus empresas generan para los bienes de capital: el sector público, como lo definimos antes, respondió por el $61 \%$ del total de la inversión fija en el país ese mismo año (34\% generado por el gasto presupuestario y $27 \%$ por las empresas estatales), lo que correspondió a un $10 \%$ respecto al PIB, contra un $6,5 \%$ del sector privado.

Pero "Las desventuras..." no se ha preocupado tan sólo por escamotear una dimensión esencial del análisis sobre el Estado, 
sino que también ha tratado de confundir el problema, mezclando deliberadamente la cuestión de gasto estatal en general y la de los gastos militares del Estado. Parecería que, desde mi punto de vista, sólo a través del gasto militar el Estado podría influir sobre la realización de las mercancías. Ahora bien, mi tesis sobre el Estado subimperislita brasileño se limita a señalar que el régimen tecnocrático-militar tiende necesariamente a promover el crecimiento de ese tipo de gasto. Lo más curioso es que, tras insistir reiteradamente en la confusión entre gasto estatal y gasto militar, "Las desventuras..." decide no tratar el tema, alegando que "lamentablemente, no hemos podido encontrar datos estadísticos que pudieran dar una idea de su significación" ${ }^{56}$

¡Singular manera de encarar la vida! Lo que no puede expresarse a través de datos estadísticos, queda fuera de cogitación. Es cierto que el análisis puramente estadístico del problema no es facilitado por el Gobierno ni por los militares, aunque parezca ser cierto también que los investigadores que podrían obtenerlos en Brasil no se han ocupado de ello. Sin embargo, ya en Subdesarrollo y revolución se indicaban elementos para abordar el problema. ${ }^{57} \mathrm{La}$ denuncia de los acuerdos de cooperación militar con Estados Unidos, en 1977, por parte del Gobierno brasileño, así como las declaraciones de distintos personeros militares respecto a la creación de un complejo industrial-militar han vuelto a poner el tema en evidencia, junto con informaciones de prensa sobre pasos dados hacia la concreción de dicho complejo. Se conoce, incluso, su localización: la zona industrial de Belo Horizonte, así como el hecho de que empresas como la Fiat y la Krupp se hallan involucradas en el mismo.

Desde distintos puntos de vista, se puede intentar evaluar la magnitud del problema. ${ }^{58}$ Lo primero que debemos considerar

56 José Serra y Fernando Henrique Cardoso, "Las desventuras de la dialéctica de la dependencia", op. cit., p. 31.

57 Cfr. Ruy Mauro Marini, Subdesarrollo y revolución, op. cit., pp. 71-73.

58 Acudiré, aquí, a las siguientes fuentes: Stockholm Internacional Peace Research Institute, World Armaments and Disarmament, SIPRI Yearbook, 1976; The International Institute for Strategic Studies (IISS), The Military Balance 1977-1978, 
es que, desde el punto de vista del presupuesto público, los gastos militares han presentado incremento, habiendo aumentado su participación en el mismo de un 15,2\% en 1963 a un $25 \%$ en 1965 (Fishlow). Estimados como porcentaje del PIB, dichos gastos han oscilado en torno a un $2 \%$, salvo años excepcionales, a juzgar por los datos que proporciona el SIPRI. El IISS maneja cifras más bajas en relación con el presupuesto público (en torno a un $10 \%$ los últimos años) y con el PIB (en torno a 1,3\%). Esta última estimativa parece dudosa, una vez que, según Fishlow, sólo las remuneraciones de los militares habían correspondido, en 1965, a un 1,3\% del PIB. Queda todavía por determinar si con remuneraciones de los militares se alude exclusivamente a las de las Fuerzas Armadas o comprenden también pagos por servicios de orden y seguridad. ${ }^{59}$

La fabricación de armamento por establecimientos militares se encuentra hoy concentrada en la Industria de Material Bélico (IMBEL), de reciente creación. De acuerdo con la información de su director saliente, general Augusto de Oliveira Pereira, ésta cumplió ya su primera fase, que consistía en la absorción de los ocho establecimientos fabriles del Ejército; la segunda fase consiste en la contratación de acuerdos de producción con la empresa privada. ${ }^{60}$ En realidad, esta línea de acción se inició en 1965, al crearse el Grupo Permanente de Movilización Industrial (GPMI), siendo una de sus primeras iniciativas la producción de vehículos militares por la Volkswagen. ${ }^{61}$ Posteriormente, con participación de capital privado, se crearon establecimientos del tipo de la

America's External Relations: Brazil, México and Venezuela, Consejo de Seguridad Nacional de Estados Unidos, marzo de 1977, mimeo, y Albert Fishlow, “Algumas reflexões sobre a política econômica brasileira após 1964", en Estudos CEBRAP, No. 7, São Paulo, enero-marzo de 1974.

59 Según el IISs, los efectivos de las Fuerzas Armadas brasileñas son actualmente los siguientes: Ejército 180.000 (110.000 conscriptos); Marina, 49.000 (3.000 conscriptos; incluye Fuerza Aérea Naval, Infantes de Marina y Cuerpo Auxiliar); Fuerza Aérea, 42.800; total, 271.800. A ello hay que agregar las Fuerzas de Seguridad Pública: 200.000 (incluye policías estatales).

60 O Estado de São Paulo, 2 de marzo de 1978.

61 Cfr. Ruy Mauro Marini, Subdesarrollo y revolución, op. cit. 
Empresa Brasileña de Aeronáutica (Embraer), cuya producción de aviones tiene como principal mercado las Fuerzas Armadas brasileñas. Más recientemente se constituyó, con capital privado nacional y de la Aerospastiale francesa (conocida por integrar el grupo que fabrica el Concorde y por su abundante suministro de material bélico a países dependientes, en especial del Medio Oriente), la Helicópteros de Brasil (Helibrás), en la que la participación estatal se realiza a través del gobierno de Minas Gerais; según informaciones de prensa, se fabricarán helicópteros para uso civil y militar, y una parte se destinará a la exportación. En la línea de fabricación de cohetes, destaca la Avibrás, que produce el Sonda-I y II, y desarrolla, en colaboración con el Centro Técnico Aeroespacial de São José dos Campos, perteneciente a la Fuerza Aérea, el Sonda-III, que alcanza $500 \mathrm{~km}$ de altura, con el cual Alemania Federal reemplazará las importaciones de cohetes de este tipo desde Estados Unidos, Inglaterra y Canadá, de acuerdo al tratado sobre cooperación científica y tecnológica firmado este año con Brasil. Ninguna de estas empresas se contempla, naturalmente, en el presupuesto público.

Finalmente, sobre la base de informaciones del SIPRI, es posible formarse una idea cualitativa del desarrollo de la producción bélica brasileña, como lo muestra el siguiente cuadro:

\section{Producción bélica brasileña, por tipos de armamento, número de modelos en su correspondiente fase de desarrollo y origen de las licencias de fabricación, 1975}

\begin{tabular}{|l|c|c|l|}
\hline \multicolumn{1}{|c|}{ Tipo de armamento } & Proyecto & Producción & \multicolumn{1}{|c|}{ Origen } \\
\hline $\begin{array}{l}\text { Aviones de combate, entre- } \\
\text { namiento y transporte }\end{array}$ & 12 & 5 & $\begin{array}{l}\text { EE.UU., Canadá, Italia, } \\
\text { Inglaterra }\end{array}$ \\
\hline Helicópteros & - & - & Italia** \\
\hline Cohetes y misiles & 3 & 5 & RFA, Francia \\
\hline Barcos pesados & - & 1 & Inglaterra \\
\hline Vehículos blindados & 2 & 1 & Francia** \\
\hline Submarinos & 1 & - & Inglaterra \\
\hline
\end{tabular}

Fuente: SIPRI Yearbook 1976.

* La producción de helicópteros se pondrá en marcha este año, en colaboración con Francia, como se ha indicado.

** Se conocen actualmente por lo menos tres tipos de vehículos blindados producidos en serie: "Urutu”, "Cascavel” y "Sucuri". 
Se observa la preponderancia de Europa Occidental, es decir, de la OTAN, en el desarrollo de la industria bélica brasileña, particularmente en lo que se refiere a armamento sofisticado. Es de notarse también que el SIPRI registra exportaciones brasileñas de aviones, tanques y vehículos blindados a Bolivia, Chile, Paraguay y Qatar; si consideramos la información de IISs, habría que agregar Uruguay, Togo y Libia. Este último país negoció en 1977 la compra de 400 unidades de vehículos blindados ("Cascavel" y "Urutu") a un precio estimado en 400 millones de dólares. ${ }^{62}$ En lo que se refiere a armamento ligero, Brasil ha alcanzado ya la autosuficiencia, según han afirmado las autoridades militares, y hace tiempo realiza exportaciones en ese renglón, particularmente a los países de América Latina.

\section{EL PAPEL DEL COMERCIO EXTERIOR EN LA REALIZACIÓN DE MERCANCÍAS}

Respecto al papel de las exportaciones en el esquema de realización de mercancías de la economía brasileña, "Las desventuras..." presenta una estimación cuantitativa sobre la base de la relación entre el saldo de la balanza comercial (negativo desde 1967 y hasta 1976) y el gasto interno bruto (consumo individual total, inversión pública y privada, gasto estatal presupuestario y saldo de las exportaciones e importaciones), para constatar lo obvio: que las variaciones positivas o negativas de dicho saldo se expresan directamente en variaciones positivas o negativas del gasto bruto. A esto aúna una curiosa manera de evaluar los datos porcentuales, a punto de considerar "insignificantes" variaciones del orden del $4,6 \%$ en mediciones macroeconómicas y poco significativas variaciones del orden del $12,5 \%$ (las exportaciones "crecieron aceleradamente entre 1965-1975, pero explicaron sólo un octavo del crecimiento de la DIB"). ${ }^{63}$ Finalmente los autores exhiben una vez más su torpeza en la manipulación de los datos,

\footnotetext{
62 O Estado de São Paulo, 13 de abril de 1977, e IISS.

63 José Serra y Fernando Henrique Cardoso, Las desventuras de la dialéctica de la dependencia, op. cit., p. 33, cursivas de los autores.
} 
al relacionar las exportaciones con el gasto interno bruto, cuyo concepto las excluye, en la medida en que se ha establecido en función del saldo del comercio exterior.

Recordemos lo ya dicho en el sentido de que la cuestión no reside tanto en saber cuál es la demanda interna, sino en conocer cómo se estructura ésta y qué relación mantiene con la demanda externa, considerando a ambas como esferas especiales de la circulación global de las mercancías producidas en Brasil. Ello no supone, ni mucho menos, que desde el lado de la oferta no crezcan las importaciones; más bien, dicho crecimiento no sólo es explicable sino compatible con la expansión de la economía subimperialista y de la economía capitalista mundial. En efecto, al extender el campo de la circulación, las exportaciones aseguran condiciones para el desarrollo de la acumulación; ${ }^{64}$ en la medida en que ésta se realiza en una economía dependiente, las exportaciones implican la reproducción ampliada de la dependencia. La economía se hace, pues, mayormente dependiente en materia de importación de mercancías, capitales y tecnología, mientras que, en sentido inverso, el flujo de mercancías, capitales y tecnología generado en el exterior se viabiliza precisamente sobre la base del crecimiento de las exportaciones brasileñas, compatibilizando pues el desarrollo de la economía subimperialista con las exigencias de la economía capitalista mundial.

Nada de ello impide que el aumento de las exportaciones corresponda a una expansión de la producción más rápida que la del consumo interno, lo que implica que la economía subimperialista deba acentuar su vuelco hacia el exterior, so riesgo de bloquear su proceso de acumulación. Si consideramos el período posterior a 1968, por ejemplo, y descartamos los años de crisis (en los que precisamente esa tendencia empezó a perfilarse, gracias a lo cual pudimos captarla), observamos que el PIB creció un 10\% al año y declinó después de 1974, lo mismo que sucedió con el PIB manufacturero, cuyas tasas de crecimiento en la fase de prosperidad

\footnotetext{
64 “[...] el comercio exterior fomenta en el interior el desarrollo de la producción capitalista [...]”. Karl Marx, El capital, t. III, p. 238.
} 
fueron de un 13\% anual; mientras tanto, en el período 1968-1976 las exportaciones aumentaron a una tasa anual del $20 \%$ y las exportaciones de manufacturas lo hicieron a un ritmo todavía más rápido, por encima del $50 \% .{ }^{65}$ De esto se deduce que, cualquiera que sea el procedimiento estadístico adoptado (y en esta materia, a diferencia de lo que afirma dogmáticamente "Las desventuras...", no hay procedimiento mejor o peor, sino más o menos adecuado a lo que se quiere demostrar), la conclusión apunta siempre a la importancia creciente de las exportaciones totales y, en particular, de manufacturas en el esquema de realización del subimperialismo brasileño, así como, por la razón indicada, a la importancia creciente del comercio exterior en su conjunto en la dinámica económica del mismo. ${ }^{66} \mathrm{El}$ hecho de que la balanza comercial arroje un saldo negativo no afecta para nada el problema; baste recordar que (en proporciones mayores, dado el distinto tipo de estructura económica y la fase de integración del mercado mundial a que corresponde) el déficit del comercio exterior de los países europeos pasó de ser el 11,4\% de las importaciones, en 1860, al 17,4\%, en 1910, con una incidencia particularmente fuerte en Inglaterra: $23,5 \%$ entre $1857-1961$ y 23,6\% entre 1909 1913. ${ }^{67}$ Esto no quiere decir que no se pueda estimar, para este último país, que la contribución directa de las exportaciones adicionales a la producción nacional bruta adicional, en términos de valor, haya sido del 24,1\%, en el período 1857-1961 a 1873-1877, y del $26,7 \%$, en el período $1893-1897$ a 1909-1913. ${ }^{68}$

\footnotetext{
65 Si tomamos los datos que proporciona "Las desventuras..." en el cuadro 3, el valor de las exportaciones totales se multiplicó por cinco en el período, y el de las exportaciones de manufacturas se multiplicó por quince.

66 Véase, por ejemplo, el análisis de un equipo de expertos fuera de toda sospecha: Carlos von Doellinger, Hugo de Castro Faria, y Leonardo Caserta Cavalcanti, $A$ política brasileira de comércio exterior e seus efeitos, 1967-1973, Río de Janeiro, IPEA/INPES, 1974.

67 Paul Bairoch, Commerce extérieur el développement économique de l'Europa au XIX ${ }^{\text {ème }}$ siècle, París, Mouton, 1976, cuadros 25 y 26.

68 Ibid., cuadro 61.
} 
Si nos preocupamos de la estructura de las exportaciones, nos sorprendemos aún más con las consideraciones que sobre el tema teje "Las desventuras...". Es así como estima despreciable la contribución de las exportaciones de manufacturas al crecimiento de la circulación, por el hecho de que "explican tan sólo un tercio del crecimiento de las exportaciones totales"; es decir, el hecho de que dichas exportaciones hayan pasado del $7 \%$ del valor exportador en 1964 al 34\% en 1976, aumentando a tasas anuales que llegan a veces al $60 \%$, a los autores no les preocupa en lo mínimo. Les preocupa aún menos cuando constatan que las exportaciones de manufacturados representan menos de un $3 \%$ del valor de la producción industrial. La creencia popular afirma que la ignorancia es la madre de la felicidad. ¿Podrían dormir tan tranquilamente nuestros "críticos" si se hubieran dado cuenta de que, mientras la producción industrial, en el período considerado (1965-1975), creció a una tasa media anual de un $11 \%$, aumentando menos de tres veces, la exportación de manufacturados lo hizo a una tasa de $15 \%$, aumentando cuatro veces? ¿Cómo explicar esa disparidad? ¿No sería necesario considerar, en lugar de cifras globales, el grado en que las exportaciones adicionales de manufacturas explican el crecimiento adicional de la demanda global de bienes industriales, así como de la producción industrial, como lo hacen autores más rigurosos?

Pero "Las desventuras..." va más lejos. Reprocha a la exportación de manufacturados por constituirse en un $50 \%$ de bienes de origen tradicional (es decir, de consumo necesario), olvidándose de que países imperialistas de la talla de Gran Bretaña seguían ostentando, en su pauta de exportación total, una participación de un $40 \%$ en textiles antes de la Primera Guerra Mundial, y que Estados Unidos entró en la fase imperialista manteniendo durante un largo período la predominancia de bienes primarios en sus exportaciones, las cuales siguen siendo en nuestros días un elemento significativo de ellas. Peor todavía, "Las desventuras..." no se da cuenta de que contradice su intención de refutar mi tesis, según la cual la debilidad del mercado interno hace que el subimperialismo brasileño deba exportar bienes de consumo 
necesario para asegurar el crecimiento de la producción. Ello no impide que haya tendencia al aumento de la exportación de bienes suntuarios y de capital más que de consumo necesario, exceptuados los productos agrícolas de gran aceptación en el mercado mundial, como la soya. Así, en 1969 las ramas cuya participación en el valor de la exportación de manufacturados excedió el 6\% (alimentos, química, metalurgia, textiles, material de transporte, material eléctrico y mecánica), representando un 70\% del total, sólo incluyeron dos que se pueden considerar "tradicionales" (alimentos y textiles), con menos del $25 \%$ del total. ${ }^{69}$ En 1977 , en las exportaciones totales, los cuatro grupos de manufacturados que comparecen entre los diez primeros de la lista sólo incluían una que corresponde a un producto de consumo habitual, aunque "no tradicional" (café industrializado), y tres que corresponden a bienes suntuarios o de capital (material de transporte, máquinas, calderas, aparatos e instrumentos mecánicos, y máquinas y aparatos eléctricos, incluidos repuestos). ${ }^{70}$

Tras intentar utilizar a las exportaciones de bienes esenciales contra mi tesis respecto a las tendencias de las exportaciones de manufacturados, "Las desventuras..." se ocupa del crecimiento de la industria de bienes de consumo necesario en sí, y pretende que dicho crecimiento debe tratarse por separado de las exportaciones de dichos productos. Así, por ejemplo, al referirse al tema, acotan: "Se dirá, con razón, que parte de ese dinamismo se explica por el crecimiento de las exportaciones, las cuales, sólo para los textiles, se elevaron dos veces y media en quantum, entre 19701974 [... . Pero el argumento no es éste" . ${ }^{71}$ Pero mis desventurados "críticos", ¡si se trata precisamente de esto!

No deja de ser patético el esfuerzo de "Las desventuras..." por confundir el asunto. Sus consideraciones sobre el aumento

69 Carlos von Doellinger, Hugo de Castro Faria y Leonardo Caserta Cavalcanti, $A$ política brasileira de comércio exterior e seus efeitos, 1967-1973, op. cit., cuadro V. 17.

70 Visão, 14 de noviembre de 1977.

71 José Serra y Fernando Henrique Cardoso, "Las desventuras de la dialéctica de la dependencia”, op. cit., p. 42 (cursivas mías). 
de la producción de bienes-salario no sólo se establecen exclusivamente en función de la demanda interna (aunque, como acabamos de indicar, saben que ese aumento tiene mucho que ver con el mercado exterior), sino que:

1) Combaten una tesis inexistente, como la de que la producción de bienes-salario no puede crecer (!).

2) Giran en torno a la cuota de ganancia, pese a que incluyen su argumentación en el apartado relativo a la superexplotación del trabajo, donde las cosas se tienen que ver desde el ángulo de la tasa de explotación y, en consecuencia, de la cuota de plusvalía.

3) Hace afirmaciones del más extraño tenor, como éstas:

a) La industria no puede elevar su cuota de plusvalía, "debido a que los trabajadores no consumen sus productos"; ${ }^{72}$ cuál es la relación entre la cuota de plusvalía y la realización del producto, sólo los autores de "Las desventuras..." lo saben; el capitalista puede realizar total o parcialmente la plusvalía contenida en la mercancía, o no realizarla en absoluto, pero esto no tiene nada que ver con la cuota de plusvalía sobre cuya base se realizó la producción de la mercancía.

b) La industria manufacturera, al reducir sus costos mediante el abaratamiento del capital constante, no haría revertir esa reducción sobre la cuota de ganancia de manera inmediata, sino a través del tortuoso procedimiento de subsidiar vía precios a la agricultura y, mediante la baja de los precios de los bienes de subsistencia, elevar su cuota de plusvalía para aumentar, finalmente, su cuota de ganancia, ${ }^{73}$ aunque situaciones similares puedan producirse en el plano de las transferencias intersectoriales de valor, por imposición de la concurrencia, es más que dudoso que el capital manufacturero las propicie de buen grado.

c) La baja de la relación producto-capital en el sector de bienes-salario durante la década de 1960 prueba "la mejora insufi-

\footnotetext{
72 Ibid., p. 37.

73 Ibid., pp. 38-39.
} 
ciente de la calidad o del uso más eficiente del capital invertido en el sector" ${ }^{74}$. En realidad, la baja de dicha relación no está indicando sino el descenso de la cuota de ganancia verificada en el Brasil de los sesenta, que vivió la recesión de 1962-1967, y se ha debido, de manera inmediata, a la caída de la demanda (y, en consecuencia, a dificultades para realizar el producto), al aumento de la capacidad instalada ociosa y, hasta 1965 , a la resistencia de los trabajadores ante la reducción de sus salarios (lo que no impidió que estos bajaran).

Para completar esos comentarios sobre el "análisis" de "Las desventuras..." respecto al sector de producción de bienes necesarios, señalamos que los autores, al constatar que ha habido inversiones en dicho sector y al creer que yo creo que esto no puede ser, se llenan de tanto júbilo que se olvidan de analizar el hecho. En realidad no lo pueden hacer, pues, como vimos, descartan en la explicación del fenómeno el dinamismo inducido por el mercado exterior y se niegan a admitir que el dinamismo del mercado interno se debe al consumo suntuario. Comoquiera que sea, "Las desventuras..." no se da cuenta de que dicha inversión sigue siendo infinitamente inferior a la que se realiza en los demás sectores de la industria. Es suficiente recurrir a la información sobre los proyectos de inversión fija, aprobados por el Consejo de Desarrollo Industrial y divulgados anualmente por el Ministerio de Industria y Comercio, para comprobar que la industria de consumo corriente no comparece allí sino con un porcentaje del valor total que varía entre un mínimo de $15 \%$ y un máximo de $21 \%$ entre 1970 y 1975; en 1976 ese porcentaje cae al 1\%, y en 1977 se eleva discretamente a un 2,7\%. Obviamente, no se puede pretender que haya mucho estímulo a la inversión tecnológica en el sector.

Dos observaciones finales. Esas tesis peregrinas sobre el comportamiento del sector de bienes de consumo necesario tienen por objeto confundir el hecho de que el dinamismo del consumo

74 Ibid., pp. 43-44. 
individual en Brasil se debe fundamentalmente al consumo suntuario, sobre la base de una fracción minoritaria de la población que participa de lo que califiqué de "sociedad de consumo a la moda de la casa"; 75 tocaremos el tema en el apartado siguiente. Por otra parte, dichas tesis se presentan en la sección titulada "La 'teoria' de la superexplotación del trabajo (o la plusvalía que nunca es relativa)", en donde, además de dicho sector, se habla mucho de la cuota de ganancia, de David Ricardo y de un sinnúmero de temas, pero casi nada de la superexplotación del trabajo en Brasil; a lo sumo, tras la confusión habitual entre superexplotación y plusvalía absoluta, que refuté en otra oportunidad, ${ }^{76}$ se citan arbitrariamente algunas cifras sobre horas trabajadas y se levantan curiosas hipótesis para explicar (ya que es imposible negar) la caída del salario real. Sin embargo, el tema es por demás importante para que permitamos que "Las desventuras..." intente escamotearlo. Pasemos, pues, a su consideración.

\section{III}

Al considerar los problemas que plantea el análisis de la superexplotación del trabajo en Brasil, es indispensable empezar por el empleo. Es, en efecto, desde esa perspectiva como nos acercamos a la situación objetiva en que los obreros entablan su relación básica con el capital: la venta de su fuerza de trabajo, que condiciona las formas mediante las cuales ésta va a ser consumida productivamente, es decir, explotada. Como tendremos ocasión de ver, la consideración del empleo contribuye a aclarar lo referente no sólo al salario, sino también a los métodos de producción de plusvalía e, incluso, a la organización de la clase obrera.

\section{LA CUESTIÓN DEL EMPLEO}

Entre 1968 y 1972, es decir, en pleno "milagro económico", la población activa brasileña creció a una tasa anual de 3,7\% y la

75 Ruy Mauro Marini, Subdesarrollo y revolución, op. cit., p. 197.

76 Ruy Mauro Marini, Dialéctica de la dependencia, op. cit., p. 92. 
ocupación en todos los sectores a 3,4\% (4,6\% en la industria manufacturera). ${ }^{77}$ La tasa de aumento de desempleo fue de un $11,4 \%$ por año. Ese aumento relativo implicó que, en términos absolutos, el desempleo abierto pasara de 663.000 personas a 1,022 millones en el período.

Señalemos algunas dificultades que presenta el manejo de estas cifras. Primero, el concepto censal de población económicamente activa (PEA) es en sí mismo tautológico, una vez que se refiere a la fuerza de trabajo presente en el mercado de trabajo. Entre los grupos de personas en edad de trabajar, excluye, por ejemplo a la mujer ocupada en el hogar, que es calificada como inactiva, aunque constituya una parcela real del ejército industrial de reserva, como lo demuestra el hecho de que, en ese período de expansión económica, la PEA femenina creció a un 3,1\% anual (incremento próximo, pues, al de la PEA masculina, que fue de 3,8\%); la PEA excluye también a los trabajadores menores de 14 años, sobre cuya significación volveremos más adelante. Segundo, el concepto de "ocupación" es altamente impreciso: se refiere tanto a los trabajadores asalariados como a los empleadores, así como a los trabajadores por cuenta propia y sin remuneración, lo que implica encubrir una importante porción del ejército industrial de reserva bajo la forma de desempleo disfrazado. Todo ello lleva a suponer que el desempleo en Brasil, en términos relativos y absolutos, es muy superior a lo que indican las cifras del desempleo abierto.

Otras dificultades presenta el manejo de las cifras. Así, si trabajamos sobre la base de los Censos Industriales y los Anuarios Estadísticos (ambos publicados bajo la responsabilidad del Instituto Brasileño de Geografía y Estadística, IBGE), podemos es-

77 "Las desventuras..." maneja, para el empleo manufacturero, cifras de $7 \%$ y hasta $9 \%$, pero esta divergencia no tiene importancia para lo que se va a exponer aquí. Hemos tomado los datos sobre el empleo de la Pesquisa Nacional de Amostra de Domicílios, cuarto trimestre de 1968 y 1972, IBGE, citados por Claudio Salm, “Evolução do mercado de trabalho, 1969-1972”, en Estudos CEBRAP, No. 8, São Paulo, abril-junio de 1974; siempre que no se indique otra cosa, los datos de la PNAD se extraerán de allí. 
tablecer para la industria textil los siguientes índices del número de obreros ocupados $(1965=100)$ : 1955, 120,3 y 1960, 106,0; sin embargo, para el año 1970 el índice puede ser de 97,0 o de 122,5, según tomemos el Anuario Estadístico (1972) o el Censo Industrial de 1970, respectivamente. Ello se debe a que los Anuarios se basan en una muestra que se ha ido reduciendo (por quiebras de empresas, defunciones, migraciones, etc.), lo que hace que la diferencia entre sus datos y los del Censo de 1960 sea mínima, pero sea grande considerablemente respecto a los del Censo de 1970. Es necesario, pues, razonar cualitativamente para sortear la dificultad: la evolución probable del empleo obrero en la industria textil parece ser la que nos presenta la serie 120,3 y 122,5 , entre 1955 y 1970, o sea, reducción absoluta entre 1955 y 1965 , con un posterior cambio de tendencia. El hecho de que la declinación absoluta de la ocupación obrera empiece en una fase de expansión económica, prosiga en la de recesión (aunque aumente en términos relativos) y cambie en el marco de la recuperación de finales de los sesenta, no tiene nada de excepcional; podemos ver cómo - pese a la expansión económica y del empleo registrada en el último período- ${ }^{78}$ una rama como la industria extractiva mineral ha reducido en términos relativos y absolutos su ocupación, la cual disminuyó en 51.000 personas entre 1968 y 1972 (PNAD).

Ello se debe a que el volumen del empleo, y por ende del desempleo, acompaña grosso modo el ciclo económico, pero depende especificamente de tres variables: la tasa de acumulación, la composición orgánica del capital y la tasa de explotación. Para contrariedad de "Las desventuras...", que aborrece las leyes,

78 La expansión del empleo, según algunos indicadores, se ha frenado a partir de 1976. Desde octubre de ese año, según el Ministerio del Trabajo, la reabsorción de la mano de obra ha sido inferior a las dispensas; en diciembre de 1976, el saldo de admisiones-dispensas indica que quedaron desempleados cerca de 23.000 trabajadores; ese saldo negativo subió a 35.000 en diciembre de 1977. Por otra parte, según el Departamento Intersindical de Estadística y Estudios Socio Económicos (DIEESE), de São Paulo, en diciembre de 1977, el 7,5\% de la PEA estaba desempleado (es decir, 3,5 millones de trabajadores sobre un total aproximado de 44 millones). 
la relación entre el empleo y esas variables puede expresarse en una ley según la cual el empleo varía en razón directa a la tasa de acumulación y en razón inversa a la composición orgánica del capital y la tasa de explotación. La relación entre las tres variables es a su vez contradictoria: el aumento de la tasa de acumulación tiende a acompañarse de la elevación de la composición orgánica y a traducirse, pues, en el incremento de la tasa de explotación (independientemente de que el incremento de la tasa de explotación, en condiciones normales, sea concomitante a la elevación de los salarios); pero el aumento de la tasa de explotación (haciendo aquí abstracción de la concurrencia entre los capitalistas) actúa en el sentido de moderar o, incluso, si es demasiado fuerte, frenar la elevación de la composición orgánica. La razón de este último fenómeno reside en que, como establece Marx, el empleo de la maquinaria depende de la diferencia entre el precio de ésta y el precio de la fuerza de trabajo que ella debe suplir. Marx observa:

En países desarrollados ya de antiguo la aplicación de máquinas a ciertas ramas industriales provoca en otras ramas una superabundancia tal de trabajo [redundancy of labour, la llama Ricardo] que, al descender el salario por debajo del valor de la fuerza de trabajo, impide el uso de maquinaria en estas industrias, llegando, no pocas veces, a hacerlo imposible, desde el punto de vista del capital. ${ }^{79}$

En países de desarrollo reciente, podríamos decir nosotros, esto se da aún con más fuerza, puesto que el empleo de maquinaria incide sobre una fuerza de trabajo que se remunera ya por debajo de su valor.

En otro plano de análisis, indiquemos que es así como se explica la inversión de capital fijo relativamente baja que en Brasil se observa en las ramas de bienes de consumo necesario; añadamos que, en el caso de la industria textil que veíamos arriba, la superpoblación que ella misma generó en su fase de moderniza-

79 Karl Marx, El capital, op. cit. 
ción, en los cincuenta, limitó —no frenó- su impulso a la renovación tecnológica, el cual volvió a agudizarse en buena parte por las posibilidades que abrió el mercado mundial a la expansión de la rama. Destaquemos, en fin, que la dictadura militar se ha preocupado por hacer efectiva la existencia de la superpoblación obrera para el capital, con lo cual ha facilitado y acelerado la rotación de la mano de obra. El mecanismo empleado ha sido el Fondo de Garantía de Tiempo de Servicio (FGTS), creado en 1967, que "Las desventuras..." curiosamente no contempla en sus consideraciones sobre el empleo. Sin embargo, se trata de un instrumento legal que, al suprimir prácticamente la estabilidad del trabajador en el empleo, resume lo esencial de la política económica del subimperialismo: crear mejores condiciones para la superexplotación del trabajo, al agilizar la acción del ejército industrial de reserva y favorecer la centralización del capital, al eliminar lo que el ex ministro Roberto Campos, quien fraguó e impuso el FGTS, calificó de "pasivo laboral" —es decir, los obreros con derecho a indemnización por despido-.

Comparando las dispensas llevadas a cabo en 38 ramas, en los períodos de 1963-1968 y 1970-1977, el Departamento Intersindical de Estadística y Estudios Socio Económicos (DIEESE), de São Paulo, ha constatado un significativo aumento en la rotación de la mano de obra, en función de la adopción del FGTS. ${ }^{80}$ La magnitud de dicha rotatividad, para el año 1974, puede ser captada a través del estudio realizado por la Fundación Instituto de Investigaciones Económicas, de la Universidad de São Paulo, cuyos resultados fueron divulgados recientemente por el Ministerio del Trabajo: la tasa media global de rotatividad era de $72 \%$ en la industria automotriz y de $63 \%$ en la eléctrico-electrónica y metalúrgica, todas ellas ramas dinámicas; como es natural, el fenómeno se acusaba en la pequeña y media empresa, ya que en aquellas que ocupaban hasta 100 empleados, la tasa de rotación, en esas ramas, era de

80 DIEESE, O Fundo de Garantia e se impacto no mercado de trabalbo, São Paulo, 1978. 
$106 \%, 110 \%$ y $95 \%$, respectivamente. ${ }^{81}$ Mencionamos ya que el problema se ha agravado a partir de 1976, al entrar en crisis el patrón de desarrollo capitalista brasileño.

Al promover la rotatividad de la mano de obra, el FGTS expande el ejército industrial de reserva bajo su forma flotante y actúa directamente sobre el nivel salarial. Como lo ha señalado el DIEESE en el estudio mencionado, las empresas dispensan a sus trabajadores en vísperas del despido colectivo y los readmiten después, o contratan nuevos, por salarios más bajos que los que había establecido el acuerdo salarial; ello hace que también las indemnizaciones por tiempo de servicio que percibe el trabajador sujeto al régimen del FGTS sean menores que las que se pagan a los que siguen bajo el antiguo régimen de estabilidad (cada vez menos, por imposición de los empresarios) y que hayan trabajado un período igual en la misma empresa.

El FGTS actúa también indirectamente sobre el nivel salarial, al desorganizar a los trabajadores. En efecto, el estudio del DIEESE muestra que, en la industria química, la tasa de sindicalización está directamente ligada al tiempo de servicio, lo que puede ser extrapolado a las otras ramas.

\section{LA CAÍDA DEL SALARIO MÍNIMO}

Sobre la tasa de efectividad del ejército industrial de reserva, y apelando a mecanismos coercitivos (como la política oficial de contento salarial y la represión policíaca), la dictadura militar ha viabilizado la tendencia del capitalismo brasileño a la fijación del salario real por debajo del valor de la fuerza de trabajo. Para demostrarlo, nos remitiremos al salario mínimo, tanto por razones teóricas como empíricas.

Antes que nada, es necesario considerar que el salario mínimo corresponde a la fuerza de trabajo simple, es decir, aquella que presenta el grado de preparación normal en la sociedad en cuestión y cuya producción demanda el tiempo de trabajo normal, así

81 Folha de São Paulo, 2 de abril de 1978. 
que expresa, por ende, el valor normal de la fuerza de trabajo; en otras palabras, la fuerza de trabajo simple corresponde a la mayoría de los trabajadores, y el trabajo simple es aquella actividad que, sin ninguna calificación especial, puede ejecutar cualquier trabajador en el goce de sus facultades. ${ }^{82}$ Por otra parte, según la Consolidación de las Leyes del Trabajo (CLT), de 1943, en su artículo 76, el salario mínimo se destina a cubrir "la satisfacción de las necesidades normales y básicas del trabajador y de su familia", es decir: alimentación, habitación, vestuario, higiene y transporte; la dieta mínima mensual, que debe corresponder a un $43 \%$ del valor del salario mínimo, fue establecida por el Decreto-Ley No.389, de 1938, e incluye algunos productos básicos que siguen siendo habituales en el consumo ordinario brasileño. ${ }^{83}$ Finalmente, según la PNAD, el 43,3\% de los empleados que en 1972 eran remunerados sólo con dinero percibía hasta un salario mínimo, y el 32,2\% percibía de uno a dos salarios mínimos; ambos tramos sumaban el $75,5 \%$ de la población trabajadora asalariada: casi 12 millones de personas sobre un total de asalariados puros de 15,5 milliones. $^{84}$

Establecida la validez del salario mínimo como categoría para el examen de la remuneración de la fuerza de trabajo en Brasil, lo primero que salta a la vista es que, si analizamos el Censo Demográfico de 1970 por tramos de ingreso, una proporción significativa de la población trabajadora percibe menos de un salario

82 Karl Marx, El capital, t. I, pp. 148-149.

83 Cfr. Teresa Mattos y Mariana Carvalho, "Efeitos da superexplotação sobre a classe operária”, en Brasil Socialista, No. 3, Lausanne, julio de 1975.

84 Estas cifras son congruentes con las que se desprenden del Censo Demográfico de 1970: si comparamos el número de trabajadores remunerados que percibían hasta un salario mínimo y el de los que percibían entre uno y dos salarios mínimos, tendríamos los porcentajes de $59,10 \%$ y $17,92 \%$, y ambas categorías sumarían el 77\%, es decir, 12,5 millones de personas sobre un total de 16 millones. La PNAD, a su vez, constata el aumento creciente de quienes ganan hasta un salario mínimo: de los trabajadores que entre 1968-1972 se incorporaron al grupo de asalariados puros, el 41,6\% lo hizo en ese tramo y el $25,3 \%$ en el que comprende entre uno y dos salarios mínimos, cuya suma corresponde al $70 \%$ del total. 
mínimo: el $40 \%$ del total; ésta es la situación de un $83 \%$ de los trabajadores del sector primario, un $23 \%$ de los de la industria y un $36 \%$ de los de servicios. A esto se suma el hecho de que el salario mínimo se redujo en un índice de 139 en 1959 (1965 = 100) a uno de 89 en 1977, lo que significa que en el período perdió el $36 \%$ de su valor. Esa tendencia declinante no se presenta de manera constante: aparte de los movimientos oscilatorios anuales, el salario mínimo real declinó a una tasa media anual de 6,8\% en el período 1959-1964, y de 3,6\%, en el período de 1964-1976; entre 1970-1975 presentó una tasa de recuperación media anual del 0,8\%, que bajó al 0,6\% entre $1975-1977 .{ }^{85}$ De allí se desprende que, en el marco de la carrera inflacionaria iniciada en 1959, los salarios salieron perdiendo, pese a la fuerte resistencia obrera; a partir de 1965, la contención salarial es impuesta por el Estado, y expresa, en el plano de la política económica, la tendencia profunda de la economía; posteriormente, la escasez de mano de obra de algunos segmentos del mercado de trabajo y el resurgimiento del movimiento sindical, entre otros factores, hacen que los salarios presenten una pequeña variación hacia arriba, inferior siempre al $1 \%$. No obstante, esa aparente mejoría hay que tomarla con precaución, por la razón ya señalada.

Comoquiera que sea, el hecho de que un $40 \%$ de la población trabajadora perciba menos de un salario mínimo y que éste exprese una remuneración siempre menor por un trabajo igual (aunque, como veremos, el trabajo no es igual, sino superior) muestra que si en 1943 el salario mínimo era la expresión del valor de la fuerza de trabajo, ha dejado de serlo. Esto se hace aún más evidente si tomamos las horas de trabajo que el obrero debe

85 Sobre la base del promedio anual real del mayor salario mínimo, datos proporcionados por la Fundación Getulio Vargas y el Ministerio del Trabajo, a precios constantes de marzo de 1978, véase O Estado de São Paulo, 29 de abril de 1978. Observamos que los datos posteriores a 1973 se ven expuestos a la poca confianza que explícitamente les confirió un documento del Ministerio de Hacienda, de Mario Henrique Simonsen, hecho público a fines de 1977, que revelaba que los índices del costo de la vida fijados por la Fundación Getúlio Vargas, para fines de revisión del salario mínimo, habían sido rebajados ese año mediante manipulación fraudulenta. 
rendir para adquirir sus medios de vida: datos del DIEESE revelan que, sólo para la adquisición de la dieta mínima que estableció la legislación, y tomando como base el salario mínimo de São Paulo (el más alto del país), el obrero rinde hoy al capitalista casi el doble del trabajo de 1959: en diciembre de ese año, el costo de esta dieta representaba 78:17 horas de trabajo semanal; en diciembre de 1965, 87:20 horas; en diciembre de 1970, 103:19 horas y, en marzo de 1978, 147:14 horas. $^{86}$

\section{LAS TENDENCIAS CONTRAPUESTAS DEL SALARIO REAL Y DEL VALOR DE LA FUERZA DE TRABAJO}

Como hemos visto, si consideráramos sólo el salario mínimo, tendríamos que concluir que es imposible la supervivencia de los trabajadores brasileños. Independientemente de que dicha supervivencia se vuelva cada vez más precaria, debido a la declinación del salario mínimo, ${ }^{87}$ habrá que tener presente que el valor de la fuerza de trabajo no se establece sobre la base del ingreso individual, sino del ingreso familiar; la remuneración del obrero como tal nos sirve tan sólo para determinar la tasa de explotación a que se encuentra sometido.

Se ha pretendido que gracias a la incorporación de más miembros de la familia obrera al mercado de trabajo, ésta ha logrado mantener su ingreso familiar. Esa aseveración no cuenta con fundamento empírico, si consideramos los datos disponibles: pese

86 Teresa Mattos y Mariana Carvalho citadas en Isto É, 29 de abril de 1978.

87 Tras reproducir una gráfica que ilustra la correlación existente entre los índices del salario mínimo y de la mortalidad infantil, Mattos y Carvalho acotan: "El índice de mortalidad infantil en Brasil es de 112 defunciones por cada mil nacimientos, sólo inferior al del Haití en América Latina. En el estado de São Paulo, el más rico del país, el índice de mortalidad infantil llegó, en 1970, a 83,64, cuando era en 1960 de 77,17. En la ciudad de São Paulo, la más grande concentración obrera del país, los números van en franca progresión, en emulación dramática con el crecimiento de las ganancias de los capitalistas: en 1960 era de 62,94 defunciones por cada mil nacidos; en 1970, era de 88,28; en 1973, era de 93 ". Teresa Mattos y Mariana Carvalho, "Efeitos da superexplotação sobre a classe operária”, op. cit., p. 41. 
a que entre 1958 y 1969 el número de miembros ocupados de la familia-tipo de la clase trabajadora de São Paulo pasó de uno a dos, el ingreso mensual real de la misma, a precios de 1958, cayó de 10,15 a 9,20 cruceiros; es decir, se redujo en un 9,4\% ${ }^{88}$ Aun si admitimos una recuperación salarial en el período posterior, el carácter modesto que ésta presentó no permite suponer que el nivel de vida de 1958 haya sido recuperado. Ahora bien, si adoptamos el supuesto (altamente dudoso, conviene observar) de que dicho nivel de vida correspondía grosso modo al valor de la fuerza de trabajo, nada nos autoriza a afirmar que hoy los trabajadores brasileños no estén siendo remunerados por debajo del valor de ésta.

Ello se agrava por el hecho de que la familia-tipo que estamos considerando se ha construido sobre la base de tres estratos de ingresos. El estrato bajo de la muestra cuenta con ingresos de hasta 500 cruceiros corrientes, o sea, ligeramente por encima de dos salarios mínimos de la época, mientras que la proporción de los asalariados que percibían hasta dos salarios mínimos era un $75 \%$ de los asalariados del país. En consecuencia, la familiatipo representa un patrón superior al grueso de los trabajadores brasileños, mientras que la que corresponde al estrato bajo se encuentra cercana a estos. Es, pues, sobre la base de este estrato que seguiremos nuestra argumentación.

Veamos el desglose de los gastos familiares del estrato bajo, comparando 1958 y 1969. El ítem que tiene mayor incidencia se refiere a alimentación, que representaba un $45 \%$ del total en 1969, habiendo aumentado respecto al otro año de referencia; lo mismo pasó con equipo doméstico, transporte, educación (que creció sensiblemente) y recreación; disminuyeron los gastos de habitación y vestuario. Eso indica una variación hacia arriba de un ítem fundamental en la determinación del valor mínimo (alimentación), así como variaciones en el mismo sentido de gastos que corresponden a lo que Marx llama valor histórico-moral. Si se tiene en cuenta que la cantidad de alimentos per cápita disminuye en la

88 DIEESE, Família assalariada: padrão e custo de vida, São Paulo, 1974, mimeo. 
familia, no es aventurado suponer que, pese al aumento relativo del ítem en el ingreso, éste haya sido sacrificado para permitir la atención de necesidades sociales, como anota el mismo DIEESE.

Así, al caer el salario por debajo del valor de la fuerza de trabajo (o al aumentar la brecha entre ambos), observamos que el obrero no tiende simplemente a reducir la atención de sus necesidades sociales, para asegurar la de sus necesidades de subsistencia, sino que trata de obtener un difícil equilibrio que le permita atender a las dos. Y no podría ser de otra manera. Al revés de lo que pretende el apologista burgués, las necesidades sociales son tan fundamentales como las estrictamente físicas para la reproducción de la fuerza de trabajo, acorde a las exigencias que plantea el mercado de trabajo y el mismo desarrollo de las fuerzas productivas. El obrero debe presentar, por ejemplo, el nivel mínimo de calificación (o educación) exigido para poder vender su fuerza de trabajo, del mismo modo como no puede prescindir de la radio, e incluso de la televisión, cuando estos medios de comunicación se generalizan, so pena de convertirse en un bruto por debajo de nivel cultural de la sociedad en que debe vivir y producir.

Resumiendo: es posible afirmar que, pese al deterioro del salario real, el obrero ha visto aumentar el valor de su fuerza de trabajo, lo que hace aún más dramática la brecha creciente entre dicho valor y el ingreso real que percibe. El problema que tendrá que resolver la clase obrera brasileña, en el marco del presente ascenso de sus luchas, no consiste, pues, tan sólo en recuperar el nivel de su salario real de hace 20 años. Bien al contrario, los trabajadores tendrían que lograr aumentos salariales que superen dicho nivel, para asegurar una remuneración acorde con el valor actual de su fuerza de trabajo.

\section{SUPEREXPLOTACIÓN Y MERCADO INTERNO}

Como se ha visto, ante el aumento del valor de su fuerza de trabajo y la caída del salario mínimo, la clase obrera brasileña, para asegurar la reproducción de su fuerza de trabajo, ha sido forzada a repartir el valor de ésta entre más miembros de la familia. Con 
ello, el capital no sólo compra con menos dinero una masa mayor de trabajo, sino que aumenta considerablemente la tasa de explotación. El concepto legal del salario mínimo (atender a la satisfacción de las necesidades básicas del obrero y su familia), se ha convertido en una burla: la contribución del jefe de familia al ingreso familiar total se redujo, en términos reales, del $84 \%$ que era en 1958, al 59\% en 1969, según el DIEESE. Hecho, por lo demás, que no deja de causar extrañeza. ¿Por quélos demás miembros de la familia trabajadora que ingresan al mercado de trabajo aportan al ingreso familiar una proporción menor que la del jefe de familia? Esto nos lleva a considerar las condiciones de trabajo propias de esos miembros: la mujer y los menores de edad.

Según la CLT, en Brasil rige el principio de a igual trabajo, salario igual. Los hechos, sin embargo, van en otra dirección. Con base en una pesquisa llevada a cabo en 1972, la Fundación Instituto de Investigaciones Económicas de la Universidad de São Paulo concluyó que los salarios de las mujeres son $57 \%$ más bajos que los de los hombres, en todas las ramas de la industria paulista. ${ }^{89}$ Esto se confirma por el hecho de que el I Encuentro de la Mujer Metalúrgica, realizado a principios de 1978 en São Paulo, puso en la primera fila de sus reivindicaciones la equiparación de salarios masculinos y femeninos, tras constatar que, en promedio, la trabajadora metalúrgica percibe una remuneración $60 \%$ inferior a la del hombre por el mismo tipo de trabajo. ${ }^{90}$ Señalemos que el bajo precio de la fuerza de trabajo femenina en el mercado corresponde a un aumento del número de mujeres incorporadas a la producción; éstas pasaron, entre 1960 y 1970, del 23,6\% de la fuerza de trabajo urbana a un $24,3 \%$ y, en el ámbito rural, del $37 \%$ al $43,4 \%$, según los censos.

Respecto a los menores de edad (entre 16 y 18 años), pese al criterio de igualdad que la preside, la ley ha establecido un mecanismo de escape: si se trata de un aprendiz, la empresa sólo le

\footnotetext{
89 Teresa Mattos y Mariana Carvalho, "Efeitos da superexplotação sobre a classe operária”, op. cit., p. 31.

90 Movimiento, 30 de enero de 1978.
} 
paga el $50 \%$ del salario mínimo en el primer año y, en el segundo y último, el 66\%. Los abusos a que esto ha dado lugar han sido clamorosos. No contento con ello, el gobierno militar de Castelo Branco decidió reducir legalmente a 50\% del salario mínimo la remuneración de los menores de 18 años. La fuerte oposición que esto suscitó entre los obreros logró que, hace tres años, se restableciera el principio de igualdad que consagra la CLT. ${ }^{91}$

Sin embargo, desde que comenzó la crisis del actual patrón de desarrollo y ante el modesto aumento que pasaron a experimentar los salarios (menos del 1\%, como vimos), la dictadura ha vuelto a sus andadas. Entre las medidas que componen el plan de reconsolidación de las leyes de trabajo, elaborado por el Ministerio del Trabajo, se pretende restablecer el horario nocturno para la mujer, suprimiendo una conquista que la clase obrera había logrado en las jornadas de 1917-1918, y reducir el salario de los menores al $50 \%$ del salario mínimo legal, bajo el pretexto de... icontener los abusos a que da lugar la legislación sobre los aprendices! ${ }^{92}$

Es, pues, en función de la caída del salario mínimo y la explotación inmisericorde de la mujer y del menor como se explica que - pese a que se haya duplicado el número de miembros de la familia que trabajan - el ingreso familiar haya disminuido. La elevación del empleo, en la coyuntura económica posterior a 1968, que "Las desventuras..." saluda con tanto júbilo (y que vimos oportunamente cómo debe ser analizada), se ha dado sobre la base del estrujamiento de la fuerza de trabajo de hombres, mujeres, jóvenes y niños, a niveles de salario que han significado enormes sacrificios para los trabajadores en lo que se refiere a la

91 El problema del trabajo del menor no se restringe a los adolescentes entre 16 y 18 años de edad. Según datos divulgados por el IBGE, los trabajadores menores de 14 años en la agricultura han pasado de 2,9 millones a 4,5 millones entre 1970 y 1975 , aumentando en un 54,5\% en todo el país. La participación de los menores de 14 años en el personal empleado en el sector ha evolucionado de un $16,5 \%$ a un $21,3 \%$ en el período considerado. Cfr. Folha de São Paulo, 4 de diciembre de 1977.

92 Véase Movimiento, 20 de marzo de 1978. 
atención de sus necesidades esenciales. Veremos, luego, que la superexplotación no se ha limitado a esta forma: el descenso del salario por debajo del valor de la fuerza de trabajo. Por ahora señalemos que la presión ejercida sobre los salarios ha resultado en el agravamiento de la distribución regresiva del ingreso y, por ende, pese al aumento del número de consumidores, en la contracción relativa del mercado interno, en lo que a la esfera baja se refiere.

Así, con base en los Censos y en la PNAD, constatamos que el tramo inferior de la PEA (50\% del total) ha visto reducir su participación en la distribución del ingreso del $17,7 \%$ en 1960, al $14,9 \%$ en 1970 , y al $11,8 \%$ en 1976 ; igual suerte corrió el tramo inmediatamente superior ( $30 \%$ del total): de $27,9 \%$ pasó a $22,9 \%$ y a $21,2 \%$ en los tres años considerados. ${ }^{93}$ Es comprensible, por tanto, que cálculos recientes para la región sur del país (que está lejos de ser la más atrasada), con base en datos oficiales de 1974, nos presentan la siguiente distribución del gasto anual familiar por clases de salario mínimo regional: menos de un salario mínimo, $0,4 \%$; de una a dos, $4,0 \%$. Esos dos grupos representan, en la muestra, el $21 \%$ del total de familias y, como vimos, la incidencia mayor en la distribución del ingreso se da precisamente hasta dos salarios mínimos. ${ }^{94}$ Pero aun si sumamos el tramo inmediatamente superior (2 a 3,5 salarios mínimos), haciendo subir la cifra al $46 \%$ de la muestra, la participación acumulada de los tres tramos en el gasto anual total no pasaría de un $15,1 \% .{ }^{95}$

Es evidente, pues, que el dinamismo del consumo individual no depende de los grupos de bajos ingresos, que comprenden a la mayoría aplastante de los trabajadores, sino del gasto suntuario que realizan los capitalistas y otros grupos que participan de la distribución de la plusvalía. Pretender que en la economía brasileña la superexplotación del trabajo no contribuye a la restricción de

\footnotetext{
93 Movimiento, 26 de junio de 1978.

94 Ibid.

95 Observemos que, según los datos del IBGE, la participación de los salarios en el valor agregado de la industria manufacturera era, en 1972, en todo el país, de un $16 \%$.
} 
la realización de mercancías, y que ésta no se apoya básicamente en el esquema de realización característico del subimperialismo (exportaciones, consumo suntuario y demanda estatal) constituye, por tanto, una burda mistificación.

\section{PROLONGACIÓN DE LA JORNADA E INTENSIFICACIÓN DEL TRABAJO}

Ahora examinemos brevemente las condiciones en que, en el proceso de producción, esa fuerza de trabajo numéricamente incrementada y en escala creciente mal remunerada sufre la explotación capitalista. Con ligereza, y en su afán de embellecer el capitalismo brasileño, "Las desventuras..." descarta la prolongación de la jornada de trabajo sobre la base de que los datos censales, en promedio y para el conjunto de la PEA, entre 1966 y 1970 no registran sino un incremento de $4,4 \%$ en las horas semanales trabajadas. Un análisis más riguroso tiene que partir de los mecanismos de prolongación que establece la misma legislación, así como del hecho, ampliamente denunciado por los obreros, de que los contratos de trabajo incluyen cláusulas que hacen obligatoria la prestación de horas extraordinarias. Debe, sobre todo, tomar en cuenta las manifestaciones de sindicatos y trabajadores respecto a la situación de la jornada de trabajo en sus empresas y ramas, provocadas tanto por las horas extras como por el sistema de turnos.

Respecto a la legislación, ésta permite que la empresa recurra normalmente a dos horas extraordinarias por día, pagadas un $20 \%$ por encima del tipo ordinario de salario (observemos que en México el pago de horas extraordinarias en días hábiles se hace sobre la base de un 100\% más y, en días de descanso, de un $150 \%$ ), las cuales pueden aumentarse en dos horas más, por "motivo de fuerza mayor o servicios inaplazables"; igualmente contempla la posibilidad de trabajo en días de reposo, mediante la autorización caso por caso. En el ya mencionado ensayo de Mattos y Carvalho se registran incontables denuncias y testimonios relativos a diversas ramas de actividad, tomados de la prensa 
y documentos sindicales. Entre ellos, la declaración del presidente del Sindicato de Metalúrgicos de São Paulo, Joaquim Santos de Andrade, en el sentido de que, en esa rama, "los obreros están trabajando 12 horas por día", a lo que añade que el 97\% de los metalúrgicos de São Paulo tiene el siguiente régimen semanal de trabajo: 8 horas diarias, 2 extraordinarias (máximo permitido normalmente por la ley) más 1 y 3 con el pretexto de compensar el sábado; sin embargo, el sábado los obreros cumplen una jornada normal de 8 horas; el total suma 66 horas semanales, y no las 48 horas que la ley establece, lo que significa un aumento del $40 \%$, y no del $4,4 \%$. En declaración a la prensa, un obrero de la misma rama revela que en enero de 1977 la Volkswagen brasileña trabajó en un régimen de horas extras que "equivalen a 3.300 empleos nuevos". ${ }^{96} \mathrm{Si}$ consideramos la prolongación que puede resultar del sistema de turnos, tendríamos - siempre para la rama metalúrgica - la siguiente situación: como el obrero debe trabajar dos semanas en el turno diurno y dos en el nocturno, al terminar las primeras dos semanas sale de la fábrica a las 19 horas, debiendo retornar a la misma el lunes; pero, como ha cambiado al turno nocturno, regresa a ésta a las 19 horas del domingo, con lo que el capitalista se apropia de 12 horas semanales de su tiempo de reposo. ${ }^{97}$

Además de esos casos ejemplares, se podría citar que, entre las pocas huelgas ocurridas en Brasil entre 1973 y 1977, detectadas por información de la prensa, tres se caracterizaron por la negativa de los obreros a trabajar horas extraordinarias, ${ }^{98}$ entre las que se destaca la de la Volkswagen en 1973, y que el programa de la Oposición Metalúrgica de São Paulo se refiere explícitamente a la cuestión de las horas extras, indicando que "además del desgaste físico [el obrero] no tiene tiempo para dedicar a la familia, a la recreación y mucho menos para el estudio o para aprender

\footnotetext{
96 Debate Proletario, No. 1, México, enero-marzo de 1978.

97 Teresa Mattos y Mariana Carvalho, "Efeitos da superexplotação sobre a classe operária”, op. cit., p. 33.

98 Movimiento, 6 de marzo de 1978.
} 
una profesión, así como para pensar y prepararse para luchar por sus derechos". 99

Nos hemos limitado deliberadamente a la industria metalúrgica, tecnológicamente avanzada y caracterizada por el predominio de la gran industria; la situación sería infinitamente peor si tomáramos la industria de transporte o la de construcción, así como, en cualquiera rama, la pequeña y mediana empresa. Por otra parte, nos hemos mantenido en la perspectiva del obrero individual y su jornada de trabajo. Sin embargo, puede hacerse referencia a la jornada de trabajo de la familia obrera, del mismo modo como se procede con el valor de la fuerza de trabajo; dicho procedimiento se vuelve, por lo demás, indispensable si trabajamos con el concepto de precio de la fuerza de trabajo, que expresa la relación entre el valor de la misma y la duración de la jornada. Desde este punto de vista, el hecho de que la familia obrera haya multiplicado por dos el número de sus miembros que trabajan apunta a que el capital ha logrado extender la jornada de trabajo familiar, aunque no necesariamente en la misma proporción.

"Las desventuras..." no menciona para nada, entre los métodos de explotación del trabajo, el aumento de su intensidad. Se trata en realidad de un fenómeno difícil de captarse a nivel de datos globales. Sin embargo, el hecho mismo de que la elevación de la productividad conlleve naturalmente un aumento de la intensidad del trabajo no nos permite descartarlo, cuando verificamos que el índice del producto real per cápita se elevó de 88 en $1959(1965=100)$ a 183 en 1976, superando la duplicación, por tanto. Los procedimientos para aumentar la intensidad son básicamente dos: el aumento de instrumentos de trabajo que el obrero debe manejar y el de la velocidad de las máquinas. Un trabajador de una industria textil señala respecto a lo primero: "Antes, un tejedor era responsable de la producción de 20 máquinas, después pasó a 25 y ahora cada cual tiene la responsabilidad de

99 Teresa Mattos y Mariana Carvalho, "Efeitos da superexplotação sobre a classe operária”, op. cit., p. 34. 
30 telares". ${ }^{100}$ Respecto a lo segundo, el I Congreso de la Mujer Metalúrgica manifestó su protesta contra el aumento constante de la velocidad de las máquinas. ${ }^{101}$

La exigencia de más trabajo al obrero mediante procedimientos extensivos o intensivos, al provocar fatiga y agotamiento, resulta en el incremento de lo que Marx llamó "los partes de guerra del ejército industrial": los accidentes de trabajo. En Brasil estos pasaron del índice 100 en 1970 al índice de 157 en 1976, y evolucionaron de 1,2 millones a casi 2 millones de casos en el período; en ese contexto, el índice de muertes pasó a 156 y el de casos de invalidez permanente a $160 .{ }^{102}$ Estos datos se refieren exclusivamente a accidentes registrados por el Instituto Nacional de Previsión Social (INPS). Las protestas que esa situación ha provocado llevaron al Gobierno a tomar cartas en el asunto y, en su mensaje al Congreso de este año, el presidente de la República anunció que el número de accidentes de trabajo había disminuido a menos de 400.000 en 1977. Sin embargo, el líder de la oposición en el Senado, Paulo Brossard, le negó veracidad a esa afirmación, atribuyéndola a la nueva ley sobre accidentes de trabajo, que obliga a la empresa a pagar al accidentado la remuneración integral del día del accidente y los 15 siguientes. “¿Quién no sabe [indagó Brossard] que, por fuerza de esa ley reciente, y no por la pregonada prevención, el INPS se ha visto aliviado de una gran masa de accidentados y accidentes?". ${ }^{103}$

Ahora bien, sabemos, con Marx, que cualquier variación en la magnitud extensiva o intensiva del trabajo hace variar en el mismo sentido el valor de la fuerza de trabajo. La prolongación de la jornada y el aumento de la intensidad del trabajo acarrean un mayor gasto de fuerza física y, en consecuencia, un desgaste mayor que, dentro de ciertos límites, incrementa la masa de medios de vida necesarios para su reposición. Los métodos de superexplotación

\footnotetext{
100 Ibid.

101 Movimiento, 30 de enero de 1978.

102 Debate Proletario, op. cit., p. 34.

103 O Estado de São Paulo, 6 de abril de 1978.
} 
arriba mencionados, relacionados con la esfera de la producción (aunque estén condicionados por la circulación, es decir, por las condiciones en que el obrero realiza la venta de su fuerza de trabajo) implican, pues, una elevación del valor de la fuerza de trabajo y refuerzan la conclusión a que habíamos llegado anteriormente. Como elemento indicativo de la ampliación de la brecha entre ese valor y el salario, es significativo el hecho ya visto de que, pese a que tiene más miembros trabajando, la familia obrera consume hoy menos alimentos per cápita.

Con sus divagaciones sobre la cuota de ganancia y el comportamiento de la industria de bienes de consumo necesario, así como con sus eruditas y pintorescas digresiones sobre David Ricardo, "Las desventuras..." no ha hecho sino maniobras de distracción destinadas a ocultar el cuadro sobrecogedor que nos presenta la superexplotación del trabajo en Brasil. Los elementos que acabamos de exponer, por su parte, no nos dan sino una pálida idea del problema, una vez que la cantidad de evidencia que al respecto nos proporciona diariamente la lucha de clases, y que se filtra a través de la prensa, nos han puesto (para darle gusto a la cultura francesa de nuestros "críticos") en un embarras de choix. El actual ascenso de las luchas obreras no hace sino multiplicar esas evidencias, al incorporar masas cada vez más amplias de trabajadores al enfrentamiento contra el régimen brutal de superexplotación que les ha impuesto el capital.

No nos queda sino llamar la atención hacia el intento mal disfrazado de "Las desventuras..." de achacar a la "considerable debilidad de los sindicatos y agrupamientos políticos afines" - junto al reaccionarismo de las fuerzas golpistas de 1964- la superexplotación que sufren los trabajadores brasileños. Llevado a su límite, ello implicaría no sólo suponer que la superexplotación es un efecto por decirlo así casual de la lucha de clases, sobre el cual el capital no tiene responsabilidad directa, y que se acaba explicando por sí mismo —el hecho, por ejemplo, de que, según "Las desventuras...", los bajos salarios se han mantenido porque... jel excedente generado se aplicó a la construcción de viviendas!- , sino también atribuir a la misma clase obrera la responsabilidad 
de que le estén arrancando el pellejo. Ahora bien, los elementos que presentamos sobre la evolución de los salarios en Brasil, después de 1959 muestran que el problema de la reducción salarial se encontraba planteado antes de la contrarrevolución desatada en 1964 y más bien fue una de las razones que hizo que ésta fuera indispensable para la burguesía. Por otra parte, ¿cómo explicar que en países como Chile, Argentina o Uruguay, donde no se puede hablar en los mismos términos de debilidad de los sindicatos y la izquierda, la clase obrera haya tenido que sufrir una superexplotación similar bajo una dictadura contrarrevolucionaria? De todos modos, las luchas actuales de los trabajadores brasileños se encargarán de mostrar hasta qué punto la superexplotación del trabajo es un elemento vital en la dinámica del capitalismo dependiente, en la medida en que tiende de nuevo a enfrentar en una lucha a muerte a patrones y obreros en torno a la cuestión de su mantenimiento o su supresión.

\section{IV}

Las razones que dan Cardoso y Serra para su "empeño en la crítica" son de orden teórico y político. Se trata de "desarticular" un pensamiento "economicista" que lleva al "voluntarismo" para así evitar que "el análisis político se vuelva al mismo tiempo ardoroso e inerme" y asegurar que el camino al socialismo pueda depender "de acciones concretas en circunstancias específicas". De esta manera se podrán impedir "desastres cuya 'corrección' pasa muchas veces por el sacrificio, incluso físico, de sectores importantes de una generación".

Vayamos por partes. Lo primero que hay que tener en cuenta es que, más que al Quijote, Cardoso y Serra se parecen a Sancho: no son los caballeros andantes del socialismo sino los escuderos de una burguesía insaciable y rapaz. Es eso lo que confiere interés a "Las desventuras...": su carácter de texto inserto en un proceso de lucha ideológica, que el ascenso de las luchas de clase en Brasil, así como en Latinoamérica, tiende a hacer más candente. Una de las cuestiones que ha sido puesta en el centro de 
la discusión es la del economicismo, que ha sido atacado desde diferentes perspectivas.

No cabe, en efecto, confundir a Cardoso y Serra con otros autores que se han ocupado del problema y que por falta de espacio no serán aquí objeto de comentario. Su ataque a mi pretendido reduccionismo económico raya en la caricatura cuando sostienen que la economía no es sino el marco en que se ejerce la lucha política, la cual corresponde a una esfera autónoma donde las opciones y consecuentes decisiones sólo se explican por la acción de las fuerzas mismas que allí actúan. Se rompe, de este modo, la unidad de análisis que convierte a la política, para decirlo con Lenin, en "la expresión concentrada de la economía" y se abandona el supuesto metodológico fundamental del marxismo, que el propio Marx expuso con tanta precisión en su "Prólogo de 1859": "El modo de producción de la vida material determina [bedingen] el proceso de la vida social, política y espiritual en general". Reducida a sí misma, la lucha política se ve así desprovista de toda base explicativa sólida.

Pero no es sólo la autonomía de la política que reivindican Cardoso y Serra: es también (y esto es lo que los distingue más netamente de otros que han criticado mi economicismo) el tomar los hechos como vienen, en su inmediatez empírica, sin la ambición de ubicarlos en un marco explicativo que les dé coherencia, los remita a las contradicciones generales a que responden y haga así posible establecer previsiones respecto a su comportamiento futuro para, sobre esta base, crear condiciones para actuar sobre ellos. Apilados unos sobre otros, como los quieren Cardoso y Serra, sin una lógica profunda que los ordene, los hechos pueden prestarse a cualquier interpretación, sin que la clase obrera disponga de un criterio que permita referirlos a las contradicciones fundamentales que los generan. Ahora bien, identificar una contradicción, por grave que ésta sea,

[...] no significa que el capitalismo sea imposible, pero sí la necesidad de su transformación en una forma superior; cuanto más fuerte se torna esa contradicción, más se desarrollan las condiciones 
objetivas de esa transformación, así como sus condiciones subjetivas, es decir, la conciencia que los trabajadores adquieren de la contradicción. ${ }^{104}$

Sin embargo, el encono de Cardoso y Serra contra mi análisis económico no los lleva a la actitud suicida de rechazar la existencia de contradicciones en el modo de producción capitalista. Por lo demás, el reformismo en sus diversas variantes ha mostrado que es posible aceptarlas sin que ello implique asumir una posición revolucionaria. No, lo que no pueden aceptar Cardoso y Serra es que se identifiquen contradicciones concretas en la sociedad latinoamericana, y en especial en la brasileña. Ante ello, claman por la pureza del marxismo, tratando de reducirlas otra vez a la contradicción abstracta, o no vacilan en echar mano de analogías formales, y por esto mismo caricaturescas, para descalificar la posibilidad de que tales contradicciones concretas sean reconocidas.

Es así que, cuando Cardoso identifica mi posición con la de los naródniks, recurre a una caricatura, además de atropellar la historia sin piedad. En su polémica con los populistas rusos, Lenin identificaba tres rasgos en los planteamientos de esa corriente: el reconocimiento del capitalismo en Rusia "como decadencia, como regresión”; el reconocimiento de la "originalidad del régimen económico ruso, en general”, y de la "del campesino con su comunidad, en particular"; y la "omisión del vínculo existente entre la “intelectualidad' y las instituciones políticas y jurídicas del país”, por una parte, y "los intereses materiales de determinadas clases sociales”, por otra. ${ }^{105}$ Como se ve, no hay ninguna relación entre las tesis en cuestión y lo que he planteado sobre la dependencia, la superexplotación del trabajo y el carácter del desarrollo capitalista brasileño. Es de suponerse, sin embargo, que a lo que Cardoso

\footnotetext{
104 Vladimir Lenin, "Respuesta al señor P. Nezhdánov", en Sobre el problema de los mercados, México, Siglo XXI, pp. 249-250.

105 Vladimir Lenin, “¿A qué herencia renunciamos?”, en Obras escogidas en doce tomos, Moscú, Progreso, s. f., t. I, p. 422.
} 
quiere aludir sea a lo que Lenin llamó romanticismo económico, lo cual, derivándose de Sismondi, se encuentra presente en el pensamiento de los populistas rusos a través de sus planteamientos respecto a la contradicción entre producción y consumo, con la consecuente necesidad de recurrir al mercado exterior. No nos contentemos, empero, con las analogías formales y veamos qué es ese subconsumismo que Cardoso denuncia en mis tesis.

Lo esencial en la posición de los populistas era el razonamiento teórico del que partían para hacer su defensa de la pequeña producción campesina. Ese razonamiento se basaba en lo que Lenin considera el error fundamental que marcó toda la economía política hasta Marx, y que introdujo Adam Smith: la confusión entre los conceptos de producción y renta y, por ende, la reducción del valor creado a la suma de la plusvalía y los salarios (capital variable), ignorando los medios de producción (capital constante). Esto les impedía entender qué es la acumulación de capital y, en consecuencia, qué es el desarrollo capitalista. Es por esa razón que, en su polémica con el populismo, Lenin se preocupa básicamente de demostrarles que, al contrario de lo que suponían, el desarrollo del capitalismo es, como lo mostrara ya Marx, el desarrollo del mercado interno. Lo que no tenía que hacer, porque esto no lo exigía su crítica a los populistas, era analizar la forma que asume el mercado interno en la economía capitalista y la contradicción entre producción y consumo individual que allí se plantea.

Pero Lenin sí tenía que preocuparse de este problema cuando se pretendía atacarlo, supuestamente desde el punto de vista del marxismo, con la afirmación errónea de que "la producción capitalista no adolece de ninguna contradicción entre la producción y el consumo" ${ }^{106}$ A esto contestaba Lenin, siguiendo a Marx, que es indispensable entender

[...] la contradicción entre la producción y el consumo, propia del capitalismo, consiste en que la producción crece con enorme

106 Vladimir Lenin, "Respuesta al señor P. Nezhdánov", op. cit., p. 245. 
rapidez, la competencia le comunica una tendencia a ampliarse sin limitaciones, mientras que el consumo (individual) crece muy débilmente, si es que crece. La condición proletaria de las masas populares no ofrece al consumo individual la posibilidad de crecer rápidamente. [...] en última instancia, el consumo debe seguir a la producción, y si las fuerzas productivas se lanzan a un aumento ilimitado de la producción, mientras el consumo se restringe, como consecuencia del estado proletario de las masas populares, la contradicción se vuelve incuestionable. ${ }^{107}$

Aclaremos bien las cosas. La contradicción entre producción y consumo individual surge de la naturaleza misma del capitalismo por el hecho de que, mientras éste registra un impulso constante de acumulación, dicho impulso choca con la desproporcionalidad existente entre los sectores de la producción y con las condiciones antagónicas de distribución. En efecto, "dentro de la producción capitalista, la proporcionalidad de las distintas ramas de producción [aparece] como un proceso constante derivado de la desproporcionalidad", ${ }^{108}$ mientras que las "condiciones antagónicas de distribución [...] reducen el consumo de la gran masa de la sociedad a un mínimo susceptible sólo de variación dentro de limites muy estrechos" ${ }^{109}$ En consecuencia, como el mercado tiene que extenderse constantemente, para hacer frente al impulso de acumulación, "la contradicción interna tiende a compensarse mediante la expansión del campo externo de la producción". ${ }^{110}$

Así es como se presenta el problema de la contradicción entre la producción y el consumo individual en la teoría marxista del capitalismo, que se presta a todo, menos a la apología del sistema. Mi análisis de la economía latinoamericana y brasileña no hace sino aplicar esa teoría a una realidad concreta, que se caracteriza por el hecho de que, a raíz de las condiciones mismas de su forma-

\footnotetext{
107 Ibid., p. 249.

108 Karl Marx, El capital, t. III, p. 254.

109 Ibid., p. 243.

110 Ibid.
} 
ción y desarrollo histórico, agrava hasta el límite las contradicciones inherentes a la producción capitalista. Es esta característica general de la economía dependiente la que la induce a extremar la desproporcionalidad entre los sectores, tanto de producción de bienes de capital respecto al de bienes de consumo, como del de bienes de consumo suntuario respecto al de bienes de consumo necesario, así como a agudizar las condiciones antagónicas de distribución, haciendo que la contradicción entre producción y consumo individual, propia de la economía capitalista en general, asuma el carácter de un divorcio progresivamente acentuado entre el aparato productivo y las necesidades de consumo de las masas.

Ahora bien: de manera subrepticia, todo el esfuerzo de "Las desventuras..." se encauza en el sentido de borrar las diferencias entre el capitalismo en los países avanzados y el capitalismo dependiente, y asimilarlos a un solo proceso: el desarrollo capitalista en la periferia y en el centro. El lector podrá buscar con lupa en el texto un indicio, por pequeño que sea, de que la discusión que se está haciendo está referida al capitalismo dependiente brasileño: encontrará sólo la idea de que en el capitalismo brasileño hay problemas y contradicciones que no tienen otra particularidad que la de darse en un país de la "periferia", o sea, en una nación capitalista joven, para usar una expresión altamente ideológica. La utilización misma del aparato conceptual "centro-periferia" en reemplazo del que corresponde a la dependencia, indica un regreso al redil de la CEPAL (la cual, por esto mismo, es tan reivindicada a lo largo del texto) y a las ilusiones desarrollistas con que ésta revistió la primera emergencia de la burguesía industrial, en la posguerra, ilusiones que, como señalamos, la vida misma destruyó. Pero hoy, los nuevos ideólogos de la burguesía brasileña están obligados a retomar esa tradición y a intentar dar credibilidad a un desarrollo capitalista brasileño al estilo norteamericano o europeo. En suma, nos encontramos ante un neodesarrollismo todavía vergonzante, pero que no tardará en ir perdiendo sus inhibiciones. 
La tímida crítica de Cardoso a la tesis de la superexplotación, que dio inicio a esta polémica, ${ }^{111}$ apuntaba ya en esa dirección. Pero hoy las cosas van más lejos. Así, en "Las desventuras..." se pretende que:

[...] aún después de 1968 y hasta 1973 [...] se mantuvo una política oficial de fuerte restricción salarial, quedando las mejoras eventualmente obtenidas en este terreno sujetas a las [fuerzas del mercado] y no en razón sea de la política gubernamental (que permaneció restrictiva) sea de la acción sindical o de la protesta social, que siguieron tan o más reprimidos o inexistentes que antes. ${ }^{112}$

Algunas rectificaciones: la restricción salarial no se mantuvo hasta 1973: se mantiene hasta boy; las "mejoras eventualmente obtenidas" no sólo han sido muy pequeñas, como demostramos anteriormente, sino que se han visto relativizadas por la manipulación de los índices del costo de la vida; y la acción sindical y la protesta social habian ganado ya cuerpo en 1973, lo que forzó a que el actual gobierno, que asumió en 1974, no sólo tuviera que prometer una "apertura política", sino también recurrir a la manipulación de dichos índices para mantener la política salarial. Pero no se trata sólo de rectificaciones, sino también de una pregunta: si las pretendidas "mejoras salariales" no se debieron al Gobierno, ni a los sindicatos, ni a la "protesta social”... ¿quién responde por ellas?

No es necesario exprimirse el cerebro para encontrar la respuesta. El mismo Cardoso, en entrevista concedida a un diario mexicano, nos explica: "En una primera etapa, la violencia represiva es la condición de la acumulación futura. Pero después,

111 Fernando Henrique Cardoso, "Nota sobre el estado actual de los estudios sobre dependencia”, en Revista Latinoamericana de Ciencias Sociales, No. 4, Santiago de Chile, 1972; véase mi respuesta en Dialéctica de la dependencia, parte II.

112 José Serra y Fernando Henrique Cardoso, "Las desventuras de la dialéctica de la dependencia”, op. cit., p. 45 (cursivas mías). 
en una segunda etapa, ya no lo es más. Eso explica que ahora los empresarios reclamen una relación directa con los obreros" ${ }^{113}$

Así, la lucha que durante estos años ha desarrollado la clase obrera - en el sentido de negociar directamente con las empresas y ejercer su derecho de reivindicación — queda borrada de un plumazo y se convierte en una generosa actitud de la burguesía. Del mismo modo como la lucha popular contra la dictadura es escamoteada, puesto que las "presiones" por la democratización "venían también, y esto hay que decirlo muy claramente, desde sectores del interior del Estado", lo que permite concluir, enérgicamente: "Si no entendemos esto, no entenderemos los cambios en Brasil. No hay que creer que el enfrentamiento es global, entre el Estado represivo por un lado y las clases dominadas por el otro". 114

No nos preocupemos demasiado en refutar la pretensión de que es la burguesía quien ha concedido aumentos salariales, a contrapelo del Estado y los sindicatos, y quien lucha por una relación directa con estos. La vida misma ha mostrado - iy con qué rapidez! — qué hay de verdad en ello: en las recientes huelgas de los obreros metalúrgicos de São Paulo, ante la lentitud del Estado para actuar, fueron los patrones quienes pidieron a gritos la represión, mientras se resistían a la relación directa con los sindicatos, que los trabajadores acabaron por imponerles. Señalemos, más bien, que Cardoso se ha desvivido por construir una alternativa para la colaboración de clases entre la clase obrera y la oposición burguesa, oposición que expresa hoy una fracción del gran capital que intenta imponer su hegemonía sobre el aparato de Estado en el marco de un régimen renovado, en el figurín que la nueva administración norteamericana ha bautizado como democracia "viable" o "gobernable" (es decir, restringida). El planteamiento de Cardoso oculta las contradicciones que dividen hoy a la bur-

113 El Gallo Ilustrado, suplemento dominical del diario El Día, No. 834, 11 de junio de 1978.

114 Ibid. Me limito aquí a los párrafos pertinentes; la crítica del conjunto de los planteamientos de Cardoso en dicha entrevista es harina de otro costal. 
guesía misma e intenta hacer creer en una contradicción entre la burguesía en su conjunto (capitaneada por las multinacionales) y el Estado. Éste, bajo el control de los militares (o un sector de estos) y una supuesta "burguesía de Estado" (los tecnócratas y la capa gerencial de las empresas estatales), ofrecería la posibilidad de una política nacionalista y democrática sobre la base de una alianza con la clase obrera organizada, es decir, los sindicatos. A esto responde la preocupación de "Las desventuras..." por la "necesidad de definir los campos de los aliados y de interferir para ampliar las brechas puestas como posibles por las contradicciones que minan la cohesión de las clases dominantes". ${ }^{115}$

Éste es el "camino al socialismo" que proponen los autores de "Las desventuras...": la subordinación de la clase obrera al Estado, teniendo como programa el desarrollo del subimperialismo brasileño. Como todo proyecto socialista burgués, se resume en la afirmación de que "los burgueses son burgueses en interés de la clase obrera", como lo señalara ya el Manifesto comunista, y deja corto al mismo La Salle, quien, como decía Marx, "estrechaba la mano de Bismarck en nombre de los intereses del proletariado".

Siendo una propuesta política que reposa sobre bases falsas, esa alianza de la clase obrera con la "burguesía de Estado" y los militares tiene tan poca viabilidad como la alianza a que en el pasado se la quería conducir con la "burguesía nacional". Pero, hasta que la historia no la cancele, los nuevos ideólogos de la

115 José Serra y Fernando Henrique Cardoso, "Las desventuras de la dialéctica de la dependencia”, op. cit., p. 48. Esa tesis se presenta, con la ambigüedad característica de Cardoso, en su libro Autoritarismo e democratização, Río de Janeiro, Paz e Terra, 1975. En un documento interno del CEBRAP, sin embargo, Cardoso la hace explícita: "Como cada uno de los sectores del capital (estatal y multinacional) busca apoyos políticos, podrá ocurrir la proposición de futuras alianzas entre sindicatos, parte del Ejército, masa urbana y la burguesía estatal en contra de las multinacionales — que buscarán apoyo en las clases medias y en la burguesía local en contra del estatismo". Fernando Henrique Cardoso, Comentários sobre el proyecto de Reichstul y Coutinho, citado por Carlos Estavam Martins, Capitalismo de Estado e modelo político no Brasil, Río de Janeiro, GRAAL, 1977, p. 330 . 
burguesía cumplen con diligencia su tarea, confiados en la autonomía de la lucha política: la de tratar de sembrar confusión y desconcierto entre la clase obrera y la izquierda, propiciando maniobras de división entre ellas. Se empeñan, pues, en desarticular todo intento de crítica al capitalismo brasileño que contenga, en sus supuestos, la negación de ese engendro que propugnan, que es el "capitalismo de Estado nacional y democrático" (la expresión es del cebrapiano Carlos Estavam Martins). En esa línea, "Las desventuras..." no es sino un paso en la escalada que pretenden llevar a cabo contra el marxismo para retirarle a la clase obrera cualquier posibilidad de dar un fundamento científico a sus luchas de clase.

Pero no basta atacar las ideas, es preciso desacreditar también el movimiento social del que brotaron. "Las desventuras..." se permite, pues, reinterpretar la historia de manera muy particular, presentando como un precio injustificado y un sacrificio inútil la práctica armada de la izquierda brasileña. Pretende ocultar que, con sus errores y sus aciertos, fue así como en Brasil (tal como se había hecho en Latinoamérica) se puso sobre el tapete, de manera concreta, la cuestión del poder y el derecho de la clase obrera y sus aliados a luchar por conquistarlo. Gracias a ello, la idea del socialismo ha dejado de ser una abstracción, un ideal sin trascendencia práctica, un tema para la discusión de intelectuales, para ganar el centro de las luchas de clases y obligar incluso a la burguesía y sus ideólogos a intentar, hoy, desviarla hacia "acciones concretas en coyunturas específicas" y un socialismo que apenas encubre su carácter de clase burgués.

La vida misma se encargará de mostrar la inutilidad de esos esfuerzos. Y lo hará por la lógica implacable de la lucha de clases que está ya encendiendo la lucha ideológica, al plantear sin tapujos las grandes cuestiones que deben discutirse, y que ha producido una nueva clase obrera, más madura y más organizada, en la que se arraiga cada vez más la conciencia de que el Estado es su enemigo de clase. Hoy el movimiento obrero brasileño exige la democracia sindical y la autonomía respecto al Estado, mientras da sus primeros pasos en la lucha política; mañana avanzará hacia 
la construcción de su partido y de la alianza con las amplias masas trabajadoras de la ciudad y del campo para hacer frente al problema del poder. Vivimos un momento en que las palabras de Lenin, en “¿Qué hacer?”, adquieren plena validez para todos aquellos que aspiran a ver el proletariado brasileño en la vanguardia de la lucha antiimperialista y socialista en América Latina:

La realización de esta tarea, la demolición del más poderoso baluarte no ya de la reacción europea, sino también (podemos decirlo hoy) de la reacción asiática, convertiría al proletariado ruso en la vanguardia del proletariado revolucionario internacional. Y tenemos el derecho de esperar que obtengamos este título de honor, que nuestros predecesores, los revolucionarios de la década del setenta, han merecido, siempre que sepamos inspirar a nuestro movimiento, mil veces más vasto y profundo, la misma decisión abnegada y la misma energía. ${ }^{116}$

116 Vladimir Lenin, “¿Qué hacer?”, en Iskra, No. 19, Moscú, 1 de abril de 1902. 